NBER WORKING PAPER SERIES

\title{
ESTIMATING TRADE ELASTICITIES: \\ DEMAND COMPOSITION AND THE TRADE COLLAPSE OF 2008-09
}

\author{
Matthieu Bussière \\ Giovanni Callegari \\ Fabio Ghironi \\ Giulia Sestieri \\ Norihiko Yamano \\ Working Paper 17712 \\ http://www.nber.org/papers/w17712
}

\author{
NATIONAL BUREAU OF ECONOMIC RESEARCH \\ 1050 Massachusetts Avenue \\ Cambridge, MA 02138 \\ December 2011
}

For helpful comments and discussions at various stages of this project, we thank James Anderson, Philippe Bacchetta, Andrew Bernard, Michele Cavallo, Steven Davis, Robert Feenstra, Joseph Gruber, Luca Guerrieri, Elhanan Helpman, Leonardo Iacovone, Jean Imbs, Olivier Jeanne, Robert Kollmann, John Leahy, Benjamin Mandel, Andrew Rose, Katheryn Russ, Linda Tesar, Shang-Jin Wei, and seminar and conference participants at ASSA 2011, the Banque de France, the Board of Governors of the Federal Reserve System, Brandeis University, BRUEGEL, the ECB, the Federal Reserve Bank of Boston, the NBER ITI Spring 2011 meeting, the workshop on "Challenges in Open Economy Macroeconomics after the Financial Crisis" at the Federal Reserve Bank of St. Louis, and the BdF/PSE Conference on "The Financial Crisis: Lessons for International Macroeconomics." We are grateful to Jonathan Hoddenbagh for carefully reviewing our theoretical work. Remaining errors are our responsibility. Work on this paper was done while Callegari was an Economist at the International Monetary Fund, and Ghironi was a Visiting Scholar at the Federal Reserve Bank of Boston. The support of these institutions is acknowledged with gratitude. The views expressed in this paper are those of the authors and do not necessarily reflect official views or policies of the Banque de France, the European Central Bank, the Federal Reserve Bank of Boston, the International Monetary Fund, the National Bureau of Economic Research, or the Organisation for Economic Co-operation and Development.

NBER working papers are circulated for discussion and comment purposes. They have not been peerreviewed or been subject to the review by the NBER Board of Directors that accompanies official NBER publications.

(C) 2011 by Matthieu Bussière, Giovanni Callegari, Fabio Ghironi, Giulia Sestieri, and Norihiko Yamano. All rights reserved. Short sections of text, not to exceed two paragraphs, may be quoted without explicit permission provided that full credit, including (C) notice, is given to the source. 
Estimating Trade Elasticities: Demand Composition and the Trade Collapse of 2008-09

Matthieu Bussière, Giovanni Callegari, Fabio Ghironi, Giulia Sestieri, and Norihiko Yamano

NBER Working Paper No. 17712

December 2011

JEL No. F10,F15,F17,F4

\section{ABSTRACT}

This paper introduces a new methodology for the estimation of demand trade elasticities based on an import intensity-adjusted measure of aggregate demand, with the foundation of a stylized theoretical model. We compute the import intensity of demand components by using the OECD Input-Output tables. We argue that the composition of demand plays a key role in trade dynamics because of the large movements in the most import-intensive categories of expenditure (especially investment, but also exports). We provide evidence in favor of these mechanisms for a panel of 18 OECD countries, paying particular attention to the 2008-09 Great Trade Collapse.

Matthieu Bussière

Banque de France

31 rue Croix des Petits Champs

75001 Paris

France

P atthieu.Eussiere@banque-france.fr

Giovanni Callegari

European Central Bank

Kaiserstrasse 29

60311 Frankfurt am Main

Germany

Jiovanni.Fallegari@ecb.int

Fabio Ghironi

Boston College

Department of Economics

140 Commonwealth Avenue

Chestnut Hill, MA 02467-3859

and NBER

fabio.ghironi@bc.edu

\author{
Giulia Sestieri \\ Banque de France \\ 31 rue Croix des Petits Champs \\ 75001 Paris \\ France \\ Jiulia. Vestieri@banque-france.fr \\ Norihiko Yamano \\ OECD \\ 2 rue Andre Pascal \\ 75775 Paris Cedex 16, Paris \\ France \\ Qrihiko.\amano@oecd.org
}




\section{Introduction}

The relation between trade flows and aggregate macroeconomic dynamics is a central question in international economics at least since Houthakker and Magee's (1969) seminal work on the estimation of income and price elasticities of trade. The issue has received renewed attention, and the debate on the determinants of trade flows has re-heated, as scholars debated the adjustment of the global trade imbalances that emerged in the 2000s and struggled to understand the dynamics of world trade in the aftermath of the global financial crisis of 2008-09. One of the key features of the global recession triggered by this crisis was a sharp contraction in world trade that reached its peak between the end of 2008 and the beginning of 2009. In 2009, global trade fell by $11 \%$ in real terms on a year-on-year basis - an unprecedented development since 1945. A distinct feature of this Great Trade Collapse (GTC; Baldwin, 2009) is that the fall in world trade has been much more pronounced than the fall in world output (real world GDP dropped by $0.7 \%$ in 2009). The change in global trade was higher than that of global output by a factor of 16 in 2009, against an average of 1.9 in the 1990-2008 period (Figure 1). The fall in international trade affected a large number of countries in all main economic regions, albeit to a different extent (Figure 2).

In this paper we re-examine the relation between trade flows and macroeconomic dynamics by developing a new methodology for the estimation of trade elasticities - specifically, the elasticity of import demand to aggregate demand - that takes into account the different import content and cyclical behavior of the different components of aggregate demand. We use the OECD Input-Output tables to show that the most procyclical components of demand (investment and exports) have a particularly rich import content, whereas the other components (private consumption and, especially, government spending) have lower import content. As a result, the fall in imports during recessions typically exceeds that of GDP by a considerable magnitude, due to the sharp reduction in the components of GDP that have the highest import content. The fall in investment is often larger than that of GDP, which triggers a sharp contraction in imports (investment being a particularly import-intensive category of expenditure). By contrast, government spending and, to a lesser extent, private consumption are not affected as much, but this does not dampen the fall in imports due to the relatively lower import content of these categories of expenditure. ${ }^{1}$ This mechanism was especially strong during the 2008-09 GTC, during which the fall in imports was ten times larger than the fall in GDP. ${ }^{2}$

Armed with these observations and intuition, we construct a new measure of aggregate demand, which we call $I A D$ (for Import-intensity-Adjusted Demand) as a weighted average of traditional

\footnotetext{
${ }^{1}$ Note that, even if investment and exports are unconditionally more volatile than GDP, and consumption is smoother, a closer look at the data shows that the most procyclical components of aggregate demand fall more sharply during recessions than they rise in expansions as we review in our empirical work.

${ }^{2}$ In the United States, for instance, the annualized fall in total investment in the last quarter of 2008 and in the first quarter of 2009 was about $24 \%$ and $31 \%$, respectively, whereas GDP - partly supported by government spendingcontracted by "only" $9.2 \%$ and $6.8 \%$.
} 
aggregate demand components (investment, private consumption, government spending, and exports) using as weights the import contents of demand computed from the OECD Input-Output tables. We show that $I A D$ is highly correlated with GDP, but more volatile on average (especially during recessions). We provide a theoretical foundation for $I A D$ as the appropriate measure of aggregate demand in empirical trade equations by relying on a translog GDP function, following Feenstra (2003a, Chapter 3), Kee, Nicita, and Olarreaga (2008), and a series of articles by Kohli (1978; 1990a,b; 1993). We show that this approach yields a parsimonious, estimable import demand equation in which imports depend on aggregate demand and relative import prices in the same fashion as implied by the traditional C.E.S. demand system, but for two important differences: First, IAD replaces the C.E.S. aggregate demand co mposite as the appropriate measure of aggregate demand. Second, the elasticity of import demand to (the correct measure of) aggregate demand is no longer restricted to one.

We take this new empirical model to the data using a panel of 18 OECD countries over the period 1985Q1-2010Q2 (the choice of countries reflects data availability: The empirical exercise requires sufficiently long time series to be able to capture a sufficient number of business cycles). We find that $I A D$ is superior to the standard, alternative measures of aggregate demand used in the literature in terms of both goodness of fit and, importantly, stability of parameter estimates. The $I A D$-based model performs remarkably well in explaining the GTC compared to the alternatives: Our basic specification explains 85\% of the average fall in imports in the G7 countries in 2009Q1 against 51\% when using GDP as explanatory variable. The regression using IAD explains $93 \%$ of the fall in imports when the additional demand component "change in inventories" is added to the regression. Most importantly, the empirical model outperforms the alternatives over the entire sample period, not just during the recent crisis, yielding estimated elasticities of imports to (the appropriate measure of) aggregate demand that are significantly less volatile across the different phases of the cycle.

According to the model, there is no major "puzzle" in the magnitude of the fall in world trade observed during the recent financial crisis: Trade fell mostly because demand crashed globally and did so particularly in its most import-intensive component-investment. Moreover, the strong relationship between exports and imports in each country (in 2005, the average import content of exports was $28 \%$ for the sample of countries, and $23 \%$ for the G7), linked to the increased internationalization of production and the strong dependence of the tradable sector on imported inputs, contributed to the simultaneity and unprecedented severity of the trade collapse. Our approach and results confirm Marquez's (1999) argument that using standard measures of aggregate demand, such as GDP or domestic demand, in trade equations may be misleading, and more so in periods in which the more import-intensive components of aggregate demand (i.e., investment and exports) fluctuate 
much more than the others, such as the 2008-09 crisis. $^{3}$

Finally, the theoretical and empirical implications of the model go some way toward explaining the so-called Houthakker-Magee puzzle. This puzzle arises when regressing real imports on measures of aggregate demand and relative import prices yields a coefficient for the demand variable that is significantly larger than one (a result first found by Houthakker and Magee, 1969, and subsequently confirmed in a large number of studies). This result is traditionally viewed as a puzzle because a coefficient above one implies that the ratio of imports to GDP should be above $100 \%$ in the long run. While this may be realistic for small open economies, it is clearly at odds with stylized facts for the United States and other large advanced economies. ${ }^{4}$ There is, however, another reason for the standard empirical finding to be viewed as puzzling, and it is that it violates a key restriction of the C.E.S. model - which is the usual theoretical underpinning of empirical investigation - that the coefficient of the demand variable should be one.

We propose a simple explanation for the puzzle, based on the cyclical behavior of aggregate demand components during recessions and their import content. Indeed, when the usual regression of imports on GDP is performed on a sample excluding recessions, we find that the HouthakkerMagee puzzle almost disappears: The coefficient of GDP is close to one. By contrast, this coefficient is usually between 2 and 3 when the sample is restricted to recessions (which violates the C.E.S. restriction). The reason why the apparent elasticity of imports to demand increases during recessions is related to the behavior of aggregate demand components during these episodes and their different import contents. By adjusting for import content in the construction of $I A D$ and departing from the C.E.S. benchmark, we find a much more stable estimated elasticity over the entire sample.

The rest of the paper is organized as follows. Section 2 reviews the related literature, paying particular attention to the ability of standard empirical models to account for the recent fall in world trade. Section 3 provides stylized facts on the import content of investment, exports, and private and government consumption, and presents the new intensity-weighted measure of demand based on the OECD Input-Output tables. Section 4 provides a theoretical foundation for the regression equation with the new measure of demand as the correct measure of aggregate demand. Section 5 turns to empirical evidence for a panel of 18 OECD countries. Finally, Section 6 concludes.

\section{Related Literature}

Our paper relates both to the recent literature on the 2008-2009 Great Trade Collapse and to the longer-standing question of how to estimate trade elasticities. Starting with the former, numerous

\footnotetext{
${ }^{3}$ Marquez (1999) questioned the usefulness of the log-linear model of trade since the elasticities of trade to income varied as trade openness modified the domestic/foreign composition of expenditure. In our model, the elasticity of imports to aggregate demand is stable because our adjusted demand measure fully reflects these composition adjustments by including time-varying import intensities and distribution of expenditure across different categories.

${ }^{4}$ Interestingly, Houthakker and Magee (1969) found that the results are not symmetric for exports and imports: The coefficient of the aggregate demand variable is much larger for imports than exports. In this paper, we focus only on imports, for which the puzzle arises most strongly.
} 
studies have attempted to shed light on the GTC (see Baldwin, 2009, for an early assessment and review).

The role of trade credit attracted immediate attention, given the financial origin of the 20082009 crisis. Analyzing the case of Japan, Amiti, and Weinstein (2011) show that exporters rely on finance more than firms that sell only domestically in order to reduce the risks that are typical of international transactions (longer payment lags, higher counterparty risks, etc.), thus making the trade sector more sensitive to changes in financing conditions; Ahn, Amiti, and Weinstein (2011) confirm this result by looking at the dynamics of export prices in those sectors where financial frictions are more significant. Feenstra, Li, and Yu (2011) incorporate the conclusions of Amiti and Weinstein (2011) in a model of heterogeneous firms and banks with incomplete information on the firms, and test the implications of the model against the dynamics of China's manufacturing firms over the period 2000-2008, confirming that exporting firms faced more severe financing constraints than domestic ones. Chor and Manova (2011) document that credit conditions had a significant effect on exports to the United States. Our analysis is not inconsistent with this evidence: While abstracting from an explicit analysis of trade credit, our results show that the demand components that are expected to be most sensitive to financing conditions (e.g., investment) experience the largest drop during times of crisis and are the main driver of import dynamics.

Using disaggregated data on U.S. imports and exports, Levchenko, Lewis, and Tesar (2010) proposed an alternative explanation, arguing that the fall in U.S. imports cannot be explained with a simple import demand model. They find that sectors used as intermediate inputs were characterized by higher decreases in both imports and exports. Our analysis complements this result, to the extent that investment is particularly rich in intermediate goods. The same authors further explored and rejected the hypothesis that U.S. imports of high-quality goods experienced larger falls than lowquality goods (Levchenko, Lewis, and Tesar, 2011).

Our work is also closely related to Bems, Johnson, and Yi (2010) and Eaton, Kortum, Neiman, and Romalis (2011). Bems et al. (2010) combine the synthetic global Input-Output table constructed by Johnson and Noguera (2009) with a Leontief production function to study the contribution of changes in the composition of demand and country specific demand shocks in the global trade contraction. They also show that, in line with our conclusions and in contrast with those of Bénassy-Quéré, Decreux, Fontagné, and Khoudour-Castéras (2009), international fragmentation of the production process can actually amplify the impact of demand shocks and justify elasticities to production larger than one in presence of asymmetric shocks across countries and sectors. Our work differs from theirs in several dimensions. First, the baseline decomposition of domestic GDP is based on expenditure components (private consumption, government consumption, investment, and exports) instead of commodity groupings (durables, non-durables, and services). Second, in our framework, changes in each individual component of spending affect imports according to their import intensity (i.e., the 
share of spending falling on imported goods), while, in Bems et al. (2010), the relation between spending components and imports is mostly driven by the share of imports linked to that type of spending in total imports. To better understand this difference, consider the case of changes in investment spending. In our framework, a change in investment spending translates into a change in the aggregate demand measure that matters for import demand according to the share of investment spending that goes (directly or indirectly) to imported goods. By contrast, in Bems et al. (2010), the relation between spending and import demand is mostly driven by the share of investment goods in total imports. Because of the level of detail of their Input-Output framework, the extension of their analysis to the time series dimension is practically very difficult. Our framework, on the opposite, is suitable for time series analysis and can be replicated easily for all the countries for which expenditure-based Input-Output tables exist.

Eaton et al. (2011) develop a Ricardian model of trade, where the Input-Output tables are used to evaluate value added and derive the component of expenditure falling on intermediate goods. Through the use of counterfactuals, they conclude that the demand composition shock is by far the most important driver of the global trade contraction; trade frictions play a much more limited role and are relevant only in China and Japan. Our work complements their study by integrating compositional shifts in the new demand measure.

The composition of domestic demand and its impact on external trade has also been the focus of work in the Dynamic Stochastic General Equilibrium literature. Erceg, Guerrieri, and Gust (2006) use the SIGMA model developed at the Board of Governors of the Federal Reserve System to show that the composition of demand in the U.S. matters for the response of trade to a variety of shocks (they explore in particular the effect of an investment shock). The main difference with our analysis is that they are primarily concerned with the impact of various shocks on investment in the context of global imbalances and their adjustment. Our study, by contrast, aims at studying the impact of composition effects and quantifying their importance across countries. In addition, Erceg, Guerrieri, and Gust (2006) focus on the composition of domestic demand only, ignoring the role of the import content of exports.

Our study is also related to the literature on the well-known Houthakker-Magee puzzle, according to which the elasticity of imports to aggregate demand (measured by total income) is too high in many countries and implies an ever growing ratio of imports to GDP. From a theoretical point of view, this result is puzzling, as the traditional C.E.S. demand system or production function implies that the elasticity of imports to aggregate demand should not be different than one. The puzzle can be seen also from another point of view. With the elasticity of exports to income usually estimated to be lower than the corresponding import elasticity, a worldwide increase in income would translate into a global trade deficit, clearly in contradiction with the need to ensure globally balanced trade. Several attempts have been made to explain the puzzle by using different measures of aggregate 
demand or price indices, or by including additional independent variables. These studies have often estimated different individual income elasticities for imports, but always well above one (see Marquez, 2002, for a discussion). In this paper, we address the puzzle from two different angles. On one hand, we address the problem from a theoretical point of view, showing how a translog specification of the GDP function (or of import demand itself) is consistent with an aggregate demand elasticity of imports that is different than one. On the other hand, we still aim at generating an empirical elasticity that is not too far from one in our estimation exercise to avoid the problem of ever increasing trade deficit in presence of income and demand growth. Our import intensity-adjusted measure of demand, indeed, generates elasticities that are considerably smaller and more stable than standard aggregate demand measures.

The focus on the composition of trade for the Houthakker-Magee puzzle also relates our work to Mann and Plück (2005). Their study, which aims to improve the estimates of U.S. trade elasticities, uses disaggregated data, matching commodity categories of imports with the corresponding domestic expenditure. They also study the impact of changes in the country composition of trade and add an independent variable to their regressions to take into account the impact of increased variety, as suggested by Feenstra (1994). Their econometric model can explain export dynamics better than the standard model, but it performs worse on imports. Focusing, as we do, only on import dynamics, Leibovici and Waugh (2011) show that an aggregate demand elasticity above one (together with other statistical features of imports and output behavior) can be obtained by considering a trade model with time-to-ship frictions and finite intertemporal elasticity of substitution. Our specification also allows for aggregate demand elasticity above one, but without relying on any particular assumption on the timing of payments and shipping.

Finally, the use of Input-Output tables in international trade analysis has antecedents to our work and that cited above. Hummels, Ishii, and Yi (2001) relied on Input-Output tables to measure and analyze the nature of vertical specialization, while Johnson and Noguera (2011) combined InputOutput tables with bilateral trade data to measure how production is shared across countries and types of goods, showing that international trade flows in value added terms are very different from those in gross production terms. ${ }^{5}$

\section{A New Measure of Aggregate Demand}

This section describes the information contained in the OECD Input-Output (henceforth, I-O) database and the methodology to construct the import contents of final demand expenditures. It also introduces our new measure of aggregate demand, $I A D$, or import intensity-adjusted aggregate

\footnotetext{
${ }^{5}$ The use of input-output tables for the estimation of trade elasticities and the forecasting of imports actually dates back to Sundararajan and Thakur (1976), who applied it to Korean data. Differently from our paper, they focused only on short-term import dynamics and did not generate a synthetic adjusted demand measure.
} 
demand. $^{6}$

\subsection{The OECD Input-Output Database and the Import Content of Expenditure Components}

The I-O tables describe the sale and purchase relations between producers and consumers within an economy. The I-O database is thus used as fundamental statistics to estimate industrial figures in national accounts. ${ }^{7}$ The growing importance of globalization has increased demand for the information offered by the Input-Output system. Examples of I-O-based globalization indicators include: the import penetration ratio of intermediate and final goods, the import content of exports (an indicator of vertical specialization), and the unit value added induced by exports. While there is a literature on the import content of exports (e.g., see Hummels, Ishii, and Yi, 2001; De Backer and Yamano, 2007; and OECD, 2011), to our knowledge, this is the first paper to compute and compare the import content by expenditure components across countries.

The most recent version of the OECD I-O database includes tables for all OECD countries and several non-member countries for the years 1995, 2000, and 2005, and/or the nearest years. Comparisons across countries are made possible through the use of a standard industry list based on ISIC Revision 3. The database covers $88 \%$ of 2005 world GDP and $64 \%$ of 2005 world population. The maximum available number of sectors is $48 .^{8}$ Imported intermediates and domestically provided inputs are explicitly separated.

Figure 3 provides a stylized illustration of the information in the OECD I-O database. For each country, there are three main matrices, one including total inter-industy flows of transactions of goods and services (domestically provided and imported) and two detailing separately domestically provided and imported flows. ${ }^{9}$ Each matrix is then divided in two main parts: The first part (in blue in the figure) describes the flows of intermediate inputs used in domestic production, the second part (in green) contains instead information on final demand expenditure.

The cells in the $Z^{d}$ section of the "domestic" matrix contain the amount of domestically produced inputs from sector $i$ (row) needed by sector $j$ (column) for production throughout the year of reference, while the cells in the $Z^{m}$ section of the "import" matrix contain the amount of imported inputs from sector $i$ (row) needed by sector $j$ (column). In the calculations below, we will use slightly modified input matrices, $A^{d}$ and $A^{m}$, where the domestic input coefficients $a_{i, j}^{d}$ contain the amount of domestically produced inputs from sector $i$ needed to produce one unit of output in sector $j$, and the imported input coefficients $a_{i, j}^{m}$ contain the imported inputs from sector $i$ needed to produce

\footnotetext{
${ }^{6} \mathrm{~A}$ more detailed explanation of the OECD I-O database and the methodology to compute import contents is in Yamano and Ahmad (2006), De Backer and Yamano (2007), and Guo, Webb, and Yamano (2009).

${ }^{7}$ This database, with its internationally harmonized tables, is a useful empirical tool for economic analysis of structural change when used in conjunction with other international databases on industrial structures, e.g., bilateral trade, labor and environmental impact statistics, etc.

${ }^{8}$ Two in Mining 2, 22 in Manufacturing, 23 in Services, and Agriculture.

${ }^{9}$ In this section we use the terms industry and sector interchangeably.
} 
one unit of output in sector $j .{ }^{10}$ In the other part of the matrices (in green), $F^{d}$ reports the final demand of domestically produced goods and services (each column refers to a different expenditure component, such as household consumption, government consumption, exports, gross fixed capital formation, change in inventories, etc.), while $F^{m}$ reports the direct imports of goods and services by final expenditure component.

We use both the "domestic" and "import" matrices to construct the import contents of four expenditure components: private consumption, government consumption, investment (proxied by gross fixed capital formation), and exports. ${ }^{11}$ Notice that we aggregate information across sectors and look at the import contents only at a macroeconomic (or country) level. In particular, the matrices allow us to compute, for each expenditure component $k$, the value of indirect imports $M_{k}^{i n d}$, i.e., the amount of imports "induced" by the expenditure on domestically provided goods and services. ${ }^{12}$ These include imports of intermediate inputs from foreign suppliers, as well as imports that are already incorporated in capital and intermediate inputs acquired from domestic suppliers. The "import" matrix, instead, allows us to compute the value of direct imports, $M_{k}^{d i r}$, for each expenditure component $k$.

Let us assume that there are $S$ sectors and $K$ final demand components in the economy, and that domestic output from each sector is used both as an intermediate input by the other sectors and to satisfy final demand. The domestic output from sector $i$ needed to satisfy the final demand from the expenditure component $k$ is then given by:

$$
x_{i, k}=\sum_{j=1}^{S} a_{i, j}^{d} x_{j, k}+f_{i, k}^{d} .
$$

In matrix format this becomes:

$$
X=A^{d} X+F^{d},
$$

where $X$ is the $S \times K$ matrix of domestic output induced by each spending component $k, A^{d}$ is the $S \times S$ matrix of domestic input coefficients, and $F^{d}$ is the $S \times K$ matrix of final demands of domestic goods and services. Domestic output can then be expressed as:

$$
X=\left(I-A^{d}\right)^{-1} F^{d}
$$

\footnotetext{
${ }^{10}$ These coefficients can be easily derived by dividing the value of each cell in $Z^{d}$ and $Z^{m}$ by the sum of the respective column (total output of sector $j$ ).

${ }^{11}$ The highly volatile nature of changes in inventories prevented us from including them in our analysis, mainly because of the impossibility to construct stable and meaningful import contents for such component of total expenditure. Moreover, changes in inventories represent on average a very small part of GDP (in the United States, for instance, they accounted for $0.3 \%$ of GDP on average in the last twenty years). We recognize, however, that changes in inventories may play a bigger role in some phases of the business cycle, in particular during recession episodes, and that their behavior may explain part of the fall in imports registered during the 2008-09 crisis (see, for instance, Alessandria, Kaboski, and Midrigan, 2010). To explore this hypothesis, in the empirical section we perform regressions where changes in inventories are added as a control variable to the basic specifications, and we find that their inclusion improves our results but is not central to them.

${ }^{12}$ Indirect imports are often associated with vertical specialization.
} 
where $\left(I-A^{d}\right)^{-1}$ is commonly referred to as the Leontief inverse.

The imports of intermediate inputs from sector $i$ induced by the expenditure on domestically provided goods and services can be calculated for each $k$ as:

$$
m_{i, k}^{i n d}=\sum_{j=1}^{S} a_{i, j}^{m} x_{j, k}
$$

In matrix format:

$$
M^{\text {ind }}=A^{m} X,
$$

or, using equation (1):

$$
M^{i n d}=A^{m}\left(1-A^{d}\right)^{-1} F^{d},
$$

where $M^{i n d}$ is the $S \times K$ matrix of indirect imports induced by each spending component $k$, and $A^{m}$ is the $S \times S$ matrix of imported input coefficients.

Direct imports are given instead directly by the following $S \times K$ matrix:

$$
M^{d i r}=F^{m}
$$

Total imports can then be expressed as the sum of direct and indirect imports, that is:

$$
M=M^{i n d}+M^{d i r}=A^{m}\left(1-A^{d}\right)^{-1} F^{d}+F^{m} .
$$

The total import content of each expenditure component $k$ is hence computed as:

$$
\omega_{k}=\frac{u M_{k}^{d i r}+u M_{k}^{i n d}}{u F_{k}^{d}+u F_{k}^{m}}=\frac{u A^{m}\left(1-A^{d}\right)^{-1} F_{k}^{d}+u F_{k}^{m}}{u F_{k}^{d}+u F_{k}^{m}},
$$

where $u$ is a $1 \times S$ vector with all elements equal to 1 and the subscript $k$ selects the $k$-th column of each matrix, corresponding to the expenditure component of interest.

In addition to the total import content $\omega_{k}$, it is also possible to derive a direct and indirect import content for each expenditure component:

$$
\begin{aligned}
& \omega_{k}^{d i r}=\frac{u M_{k}^{d i r}}{u F_{k}^{d}+u F_{k}^{m}}, \\
& \omega_{k}^{i n d}=\frac{u M_{k}^{i n d}}{u F_{k}^{d}+u F_{k}^{m}},
\end{aligned}
$$

where the indirect import content tells us the share of intermediate imported inputs per unit of final demand, and the direct import content tells us the share of imported final goods and services. Notice that the direct import content of exports is equal to zero as re-exports of goods and services are excluded from the analysis. ${ }^{13}$ Table 1 shows the evolution of import contents (total, direct, and

\footnotetext{
${ }^{13}$ We are aware that the amount of processing trade is relatively large for some countries, such as China and other emerging economies, so that our numbers for the import content of exports are biased downward in these cases. In this paper, however, we have chosen not to consider re-exports in line with other OECD publications (see, among others,
} 
indirect) of the main GDP expenditure components over time for a large set of countries. ${ }^{14}$

\subsection{Import Intensity-Adjusted Aggregate Demand}

Empirical trade models typically use measures of aggregate demand, such as GDP or domestic demand, ignoring the fact that different components of expenditure have different import contents. Figure 4 shows the import contents of private and government consumption, investment, and exports for our panel of 18 countries based on the 2005 I-O tables, together with the average across all countries and the G7. ${ }^{15}$

As Figure 4 shows, the import content of government consumption is low across all countries (government spending mostly includes non-tradables, such as services, and a high share of domestically produced goods, e.g., for the defense industry). Turning to the other two main components of domestic expenditure, investment has a higher import content than private consumption in all countries but the UK. Finally, exports are also very import-intensive as shown by the purple bars in the figure: On average the import content of exports is $28 \%$, with peaks of about $40 \%$ for small open economies such as Belgium or Portugal and some emerging countries (see Table 1 for a comparison across a larger set of countries). The country order of import content shares is mainly determined by two factors: availability of intermediate suppliers (country size) and position in the global production network. Japan and the United States, for instance, have relatively more domestic suppliers for their production network than most European countries, which rely on more foreign products for their production. This explains why the import contents of Japanese and U.S. exports are rather low (although, in the case of Japan, rising over time).

Consistent with these findings, imports tend to be strongly correlated on average with exports and investment and, to a lesser extent, private consumption, while they appear to be uncorrelated with government consumption, as shown in Figure 5.

In this paper, we focus on imports, and we propose a new measure of aggregate demand that reflects the import intensity of the different components of domestic expenditure and the import content of exports. We call this import intensity-adjusted measure of demand $I A D$, for "importadjusted demand", and construct it, country by country, as follows:

$$
I A D_{t}=C_{t}^{\omega_{C, t}} G_{t}^{\omega_{G, t}} I_{t}^{\omega_{I, t}} X_{t}^{\omega_{X, t}}
$$

where $C$ stands for private consumption, $G$ for government consumption, $I$ for investment, and $X$ for exports, included to take the import content of export demand into account. In logarithms:

OECD, 2011, pp. 178-179). Moreover, in our empirical analysis we focus mainly on advanced OECD economies for which the amount of re-exports is smaller, so that our results should not be significantly affected.

${ }^{14}$ We report the values for 1995, 2000, and 2005 in Table 1. For some countries, 1985 and 1990 values exist and are available upon request.

${ }^{15}$ The countries we focus on are Australia, Belgium, Canada, Denmark, Finland, France, Germany, Italy, Japan, Korea, Netherlands, New Zealand, Norway, Portugal, Spain, Sweden, the UK, and the U.S. 


$$
\ln I A D_{t}=\omega_{C, t} \ln C_{t}+\omega_{G, t} \ln G_{t}+\omega_{I, t} \ln I_{t}+\omega_{X, t} \ln X_{t} .
$$

The weights, $\omega_{k, t}, k=C, G, I, X$, are the total import contents of final demand expenditures and are constructed as explained in Section 3.1. They are time varying and normalized in each period such that their sum is equal to one. ${ }^{16}$

We shall show that $I A D$ represents a better measure of aggregate demand than domestic demand or GDP to explain import fluctuations since it weighs each GDP component according to its import content. Two facts are also worth noting: First, the relative import contents of the main components of GDP are substantially different from their shares in GDP (on average, private consumption represents $60 \%$ of GDP in our panel of countries, against $20 \%$ of government consumption and investment $\left.{ }^{17}\right)$. Second, different components of aggregate demand showed very different behaviors during the crisis. Indeed, investment and exports fell much more than private and government consumption in most countries. The fact that investment falls more sharply than other categories of expenditure during recessions is a robust stylized fact. ${ }^{18}$ Thus, the fact that standard GDP computations neglect that investment and exports tend to have larger import content than private consumption and government consumption may explain why the fall in trade during the 2008-09 crisis was larger than suggested by estimated elasticities based on GDP as the measure of demand.

Table 2 reports the descriptive statistics for quarterly changes in $I A D$, GDP and imports, $M$, for the full set of 18 countries and for the G7 over the entire sample period and also distinguishing between recessions (defined as two consecutive quarters of negative GDP growth) and expansions. The table shows that $I A D$ is highly correlated with GDP - the average correlation coefficient over the entire sample being 0.66 for the full set of countries and 0.77 for the G7-and also strongly correlated with imports - the coefficient being 0.62 and 0.70 , respectively-, while the correlation between GDP and imports is much lower, especially during expansions. Moreover, both first and second moments of $I A D$ are closer to those of imports than the moments of GDP: In particular, $I A D$, is significantly more volatile than GDP during recessions - when its average standard deviation is twice that of GDP - but also during expansionary phases.

Figure 6 looks explicitly at the behavior of GDP, its components, and $I A D$ during the two years after the start of a recession (defined as before) for our panel of 18 OECD countries and the G7. ${ }^{19}$

\footnotetext{
${ }^{16}$ Since the I-O tables allow us to compute import contents for the different demand components only every five years, we linearly interpolate the available points to construct quarterly weights. For the period after 2005, we assume the same weight as in 2005. For some countries, the I-O tables do not provide data before 1995. In these cases, we use the same weight as in 1995 for the period before.

${ }^{17}$ Exports and imports also represent on average $20 \%$ of GDP.

${ }^{18}$ It is consistent with the standard property of the business cycle for many countries that investment is more volatile than GDP, while consumption is smoother.

${ }^{19}$ To obtain the lines in Figure 6, we performed panel regressions for each of the variables, where the regressors are an indicator of recession start (equal to 1 in the first quarter of a recession), the lags of such indicator, and countryspecific dummy variables. The methodology is similar to that of IMF (2010). The resulting line for each variable can be interpreted as its unconditional average cumulative fall during recession periods.
} 
Panels $\mathrm{A}$ and $\mathrm{C}$ show the average fall in each variable during all the recessions that occurred between 1985 and 2007, whereas panels B and D refer to the 2008-09 recession only. The figures also include the behavior of GDP and the new measure of demand, IAD. As panel A shows, investment is the demand component that exhibits the largest fall during recessions, dropping by $16 \%$ on average two years after the start of a recession. Trade variables also fall substantially in the first year and then gradually recover. Government consumption does not generally fall during recessions (possibly because it is used for counter-cyclical policy), while private consumption falls less than GDP on average. Our adjusted measure of demand falls by $8.3 \%$ on average after two years, 2.5 percentage points more than GDP, and its dynamics follow quite closely those of imports during recessions. Focusing on the 2008-09 recession, the first major difference is the scale of the vertical axis, which is almost doubled: Investment fell by more than $20 \%$ on average and did not exhibit any sign of recovery after two years. The second major difference is the size of the average fall of trade, which in the case of imports is more than twice the size observed during previous recessions and in the case of exports is higher by a factor of five. This last feature illustrates clearly the global nature of the 200809 recession: Exports on average fell modestly during previous recessions, partly because external demand was sustained by trading partners in a different phase of the cycle. In contrast, during 2008-09, 17 out of the 18 countries experienced a recession (the only exception being Australia), driving down external demand for each country in the sample. This global effect, together with the propagation/synchronization mechanism implied by increased vertical integration, helps explain why the fall in trade in 2008-09 was exceptionally large and synchronized. Finally, panel B shows that $I A D$ exhibits a drop of about $15 \%$ two years after the start of the crisis, reflecting significant export and investment losses, against a realized drop in GDP of "only" 7.5\%. The story is rather similar in terms of behavior of different components of demand and differences in magnitude between past recessions and the 2008-09 one when looking at the G7 countries.

Having constructed the new aggregate demand measure and taken an initial look at its empirical properties, we next provide a theoretical foundation for its role in the determination of import demand and its inclusion in trade regressions of the form commonly featured in the literature.

\section{IAD Theory}

The traditional theoretical underpinning of much empirical trade literature is the C.E.S. demand system. Under C.E.S. preferences, (log) import demand is determined by

$$
\ln M_{t}=\ln D_{t}+\beta_{P} \ln P_{M, t}
$$

where $D_{t}$ is aggregate demand (a C.E.S. aggregator of domestic and imported goods) and $P_{M, t}$ is the relative import price. In the standard framework, the basket $M_{t}$ is itself a C.E.S. aggregate of individual imports. Equation (2) restricts the elasticity of imports to aggregate demand to be equal 
to one, while $\beta_{P}$ can take any negative value (estimates based on aggregate macro data typically put its absolute value at or near 1.5-although Corsetti, Dedola, and Leduc, 2008, argue in favor of a value between zero and one - while estimates based on more disaggregated data usually find higher absolute values). The C.E.S. demand equation (2) is the foundation of regressions of the form:

$$
\Delta \ln M_{t}=\delta+\beta_{D} \Delta \ln D_{t}+\beta_{P} \Delta \ln P_{M, t}+\varepsilon_{t},
$$

where $\Delta$ denotes first difference (on account of non-stationarity), $\delta$ is a constant, and $\varepsilon_{t}$ is the error term. The Houthakker-Magee puzzle is the finding of Houthakker and Magee (1969) and many subsequent studies that the estimated elasticity of imports to aggregate demand, $\hat{\beta}_{D}$, is significantly above one.

Our goal in this section is to provide a theoretical foundation for a (log) import demand equation that is consistent with the regression equation (3), does not restrict the elasticity of imports to aggregate demand to be one, and in which aggregate demand takes the form of the IAD aggregatorin levels, a Cobb-Douglas function with time-varying weights - of private consumption, government consumption, investment, and exports. The goal of obtaining an unrestricted theoretical elasticity of imports to aggregate demand raises the question whether such unrestricted elasticity would automatically imply that the Houthakker-Magee puzzle is no longer a puzzle. We argue that this conclusion would not be correct. The fact that the C.E.S. demand system restricts the coefficient of aggregate demand to one implies that any estimate that is statistically different from one is a puzzle - even estimates below one - if one takes the C.E.S. system literally. The particular manifestation of the puzzle known as the Houthakker-Magee puzzle is that the estimate is significantly larger than one, which (in conjunction with a smaller estimate for the elasticity of exports) raises the issue of sustainability of a country's external position. A demand system that does not restrict the coefficient of aggregate demand in the import equation to one does not in itself imply resolution of the economic puzzle that a coefficient significantly above one can derail sustainability. The model we propose in this section implies that estimates below and above one are not necessarily puzzling from the perspective of consistency with the theoretical demand system (thus allowing for meaningful degrees of freedom in what one expects the estimation procedure to deliver relative to the theory). But it is still the case that the estimated elasticity of imports to aggregate demand ought to be close to one (or below, or not much above) to avoid puzzling implications for sustainability.

The theoretical foundation for the regression equation with $I A D$ as the correct measure of aggregate demand and an unrestricted elasticity is a production possibilities frontier with imports understood to be inputs in total output determination and aggregated into a single variable. The construct follows Feenstra (2003a, Chapter 3) and a series of articles by Kohli (1978; 1990a,b; 1993), but we think of output as demand-driven on the way to thinking of imports as demand-driven. ${ }^{20}$

\footnotetext{
${ }^{20}$ We are grateful to James Anderson for suggestions that led to the development of this foundation.
} 
The total output (or GDP) function in Feenstra (2003a, Ch. 3) is usually written as a function of prices. Omitting time indexes to save on notation, let $Y$ be the vector of outputs, $P$ be the price vector of these outputs, $M$ be imports, $P_{M}$ be the price vector of imports, and $F$ be the vector of primary factors of production. ${ }^{21}$ Given a convex technology $T$ (function of $Y, M$, and $F$ ), the efficient economy is assumed to determine outputs of individual goods and imports to maximize total output (GDP) subject to prices and the endowments of primary factors. Let GDP be described by the function $v(\cdot)$ of $P, P_{M}$, and $F$ defined as:

$$
v\left(P, P_{M}, F\right) \equiv \max _{Y, M} P Y-P_{M} M \mid Y \in T(Y, M, F) .
$$

In this setup, the demand for imports is given by the partial derivative $-v_{P_{M}}\left(P, P_{M}, F\right)$, while the supply of output is given by $v_{P}\left(P, P_{M}, F\right)$.

To think now of imports as demand-driven, we need to use the market clearing condition for output, $v_{P}\left(P, P_{M}, F\right)=D$, where $D$ is the demand vector. Define the new GDP function $V\left(D, P_{M}, F\right)$ as function of the demand vector $D$, import prices $P_{M}$, and primary factors $F$ as follows. Let

$$
\tilde{v}\left(D, P_{M}, F\right) \equiv \min _{P} v\left(P, P_{M}, F\right)-P D
$$

The first-order condition for this problem is the market clearing condition for output, which can be solved for the market clearing price. Then we can write the GDP function as

$$
V\left(D, P_{M}, F\right) \equiv \tilde{v}\left(D, P_{M}, F\right)+D \tilde{v}_{D}\left(D, P_{M}, F\right) .
$$

Import demand is therefore given by the partial derivative

$$
M\left(D, P_{M}, F\right)=-V_{P_{M}}\left(D, P_{M}, F\right)
$$

Given this result, we can obtain the desired import demand equation in two ways: One relies on assuming that the GDP function is approximated by a translog function, in the spirit of Kohli (1978; 1990a,b; 1993) and Feenstra (2003a, Ch. 3). ${ }^{22}$ The alternative consists of imposing the translog assumption directly on the import demand function in (5). We show the result for each of these approaches below. ${ }^{23}$

\footnotetext{
${ }^{21}$ All prices are in real terms.

${ }^{22}$ See also Kee, Nicita, and Olarreaga (2008), who focus on the estimation of import demand elasticities to prices, and Harrigan (1997).

${ }^{23}$ The translog function has been shown to have appealing empirical properties in a variety of contexts in addition to the work reviewed in Feenstra (2003a, Ch. 3). For instance, Bergin and Feenstra (2000, 2001) show that a translog expenditure function makes it possible to generate empirically plausible endogenous persistence in macro and international macro models by virtue of the implied demand-side pricing complementarities. Feenstra (2003b) shows that the properties of the translog expenditure function used by Bergin and Feenstra (2000, 2001) hold also when the number of goods varies. Bilbiie, Ghironi, and Melitz (2007) find that translog preferences and endogenous producer entry result in markup dynamics that are remarkably close to U.S. data. Rodríguez-López (2011) extends the model of trade and macro dynamics with heterogeneous firms in Ghironi and Melitz (2005) to include nominal rigidity and a translog expenditure function. He obtains plausible properties for exchange rate pass-through, markup dynamics, and cyclical responses of firm-level and aggregate variables to shocks.
} 


\subsection{Translog GDP Function}

Suppose that the GDP function $V\left(D, P_{M}, F\right)$ is described by the following translog function: ${ }^{24}$

$$
\begin{aligned}
\ln V\left(D, P_{M}, F\right) & =\alpha+\sum_{k} \mu_{k} \ln D_{k}+\mu_{P} \ln P_{M}+\sum_{f} \mu_{f} \ln F_{f} \\
& +\frac{1}{2} \sum_{k} \sum_{j} \lambda_{k j} \ln D_{k} \ln D_{j}+\frac{1}{2} \lambda_{P}^{2}\left(\ln P_{M}\right)^{2}+\frac{1}{2} \sum_{f} \sum_{h} \lambda_{f h} \ln F_{f} \ln F_{h} \\
& +\sum_{k} \sum_{f} \phi_{k f} \ln D_{k} \ln F_{f}+\ln P_{M} \sum_{k} \phi_{k} \ln D_{k}+\ln P_{M} \sum_{f} \phi_{f} \ln F_{f} .
\end{aligned}
$$

The translog function (6) implies that the share of imports $M$ in GDP, $s_{M}^{V}$, is linear in the $(\log )$ components of aggregate demand:

$$
\begin{aligned}
s_{M}^{V} & \equiv \frac{\partial \ln V\left(D, P_{M}, F\right)}{\partial \ln P_{M}}=\frac{P_{M} V_{P_{M}}\left(D, P_{M}, F\right)}{V\left(D, P_{M}, F\right)}=\frac{P_{M}(-M)}{V} \\
& =\mu_{P}+\lambda_{P} \ln P_{M}+\sum_{k} \phi_{k} \ln D_{k}+\sum_{f} \phi_{f} \ln F_{f} .
\end{aligned}
$$

Second-order terms in the translog GDP function are crucial for the import share to deviate from the Cobb-Douglas share $\mu_{P}$. Note that, since imports are an input to GDP, the import share $s_{M}^{V}$ is negative. In (7), we used the short-hand notation $-M \equiv V_{P_{M}}\left(D, P_{M}, F\right)$ and $V \equiv V\left(D, P_{M}, F\right)$.

Consider now the absolute value of the import share: $P_{M} M / V$. Differentiating this expression and defining percent deviations from steady state, we have:

$$
\left(\hat{P}_{M}+\hat{M}-\hat{V}\right)\left|\bar{s}_{M}^{V}\right|
$$

where, for any variable $Q, \hat{Q} \equiv d Q / \bar{Q}, d$ denotes the differentiation operator, and overbars denote levels along the steady-state path. Note that, for small enough perturbations, $\hat{Q} \equiv d Q / \bar{Q} \approx d \ln Q=$ $\ln Q-\ln \bar{Q}$. It follows that:

$$
\begin{aligned}
\left(\hat{P}_{M}+\hat{M}-\hat{V}\right)\left|\bar{s}_{M}^{V}\right| & \approx\left(d \ln P_{M}+d \ln M-d \ln V\right)\left|\bar{s}_{M}^{V}\right| \\
& \approx-\left(\lambda_{P} d \ln P_{M}+\sum_{k} \phi_{k} d \ln D_{k}+\sum_{f} \phi_{f} d \ln F_{f}\right)
\end{aligned}
$$

where the second approximate equality follows from differentiating the expression of the import share in (7) after changing sign. Rearranging this equation yields:

$$
d \ln M \approx\left(d \ln V-d \ln P_{M}\right)-\frac{1}{\left|\bar{s}_{M}^{V}\right|}\left(\lambda_{P} d \ln P_{M}+\sum_{k} \phi_{k} d \ln D_{k}+\sum_{f} \phi_{f} d \ln F_{f}\right) .
$$

\footnotetext{
${ }^{24}$ See Feenstra (2003, Ch.3) for the parameter restrictions that are usually imposed on the translog GDP function (as function only of prices and factor endowments) to ensure homogeneity of degree 1 and symmetry. Some restrictions would be different for our transformed function. However, we do not rely on any of these restrictions below, so they can be safely ignored for our purposes.
} 
Differentiating (6), we have:

$$
\begin{aligned}
d \ln V & =\sum_{k} \mu_{k} d \ln D_{k}+\mu_{P} d \ln P_{M}+\sum_{f} \mu_{f} d \ln F_{f} \\
& +d\left[\begin{array}{c}
\frac{1}{2} \sum_{k} \sum_{j} \lambda_{k j} \ln D_{k} \ln D_{j}+\frac{1}{2} \lambda_{P}^{2}\left(\ln P_{M}\right)^{2}+\frac{1}{2} \sum_{f} \sum_{h} \lambda_{f h} \ln F_{f} \ln F_{h} \\
+\sum_{k} \sum_{f} \phi_{k f} \ln D_{k} \ln F_{f}+\ln P_{M} \sum_{k} \phi_{k} \ln D_{k}+\ln P_{M} \sum_{f} \phi_{f} \ln F_{f}
\end{array}\right] .
\end{aligned}
$$

For simplicity, assume that all the second order terms in (6) are constant at their steady-state levels (or that their variation around the steady-state path is negligible). Then,

$$
d \ln V=\sum_{k} \mu_{k} d \ln D_{k}+\mu_{P} d \ln P_{M}+\sum_{f} \mu_{f} d \ln F_{f}
$$

and substituting this into (8) yields:

$$
\begin{aligned}
d \ln M & \approx\left(\sum_{k} \mu_{k} d \ln D_{k}+\mu_{P} d \ln P_{M}+\sum_{f} \mu_{f} d \ln F_{f}-d \ln P_{M}\right) \\
& -\frac{1}{\left|\bar{s}_{M}^{V}\right|}\left(\lambda_{P} d \ln P_{M}+\sum_{k} \phi_{k} d \ln D_{k}+\sum_{f} \phi_{f} d \ln F_{f}\right) \\
& =\sum_{k}\left(\mu_{k}-\frac{1}{\left|\bar{s}_{M}^{V}\right|} \phi_{k}\right) d \ln D_{k}+\left(\mu_{P}-1-\frac{1}{\left|\bar{s}_{M}^{V}\right|} \lambda_{P}\right) d \ln P_{M} \\
& +\sum_{f}\left(\mu_{f}-\frac{1}{\left|\bar{s}_{M}^{V}\right|} \phi_{f}\right) d \ln F_{f} .
\end{aligned}
$$

Introduce time indexes, allow for time variation in the coefficients on aggregate demand components, and define:

$$
\begin{aligned}
\beta_{k, t} & \equiv \mu_{k, t}-\frac{1}{\left|\bar{s}_{M}^{V}\right|} \phi_{k, t}, \\
\beta_{P} & \equiv \mu_{P}-1-\frac{1}{\left|\bar{s}_{M}^{V}\right|} \lambda_{P}, \\
\beta_{f} & \equiv \mu_{f}-\frac{1}{\left|\bar{s}_{M}^{V}\right|} \phi_{f},
\end{aligned}
$$

where we impose the restrictions $\beta_{k, t}>0$ and $\beta_{P}<0$. Note that the first definition implicitly assumes that the share of imports in GDP is constant along the steady-state path. Using these definitions,

$$
d \ln M_{t} \approx \sum_{k} \beta_{k, t} d \ln D_{k, t}+\beta_{P} d \ln P_{M, t}+\sum_{f} \beta_{f} d \ln F_{f, t} .
$$

First-differencing this relation yields:

$$
\Delta d \ln M_{t} \approx \sum_{k} \Delta\left(\beta_{k, t} d \ln D_{k, t}\right)+\beta_{P} \Delta d \ln P_{M, t}+\sum_{f} \beta_{f} \Delta d \ln F_{f, t} .
$$

Assume that the effect of growth in the deviations of factor endowments from the steady-state 
path is also negligible: $\sum_{f} \beta_{f} \Delta d \ln F_{f, t} \approx 0 .{ }^{25}$ Then,

$$
\Delta d \ln M_{t} \approx \sum_{k} \Delta\left(\beta_{k, t} d \ln D_{k, t}\right)+\beta_{P} \Delta d \ln P_{M, t}
$$

or:

$$
\Delta \ln M_{t}-\Delta \ln \bar{M}_{t} \approx \sum_{k} \Delta\left[\beta_{k, t}\left(\ln D_{k, t}-\ln \bar{D}_{k, t}\right)\right]+\beta_{P} \Delta\left(\ln P_{M, t}-\ln \bar{P}_{M, t}\right) .
$$

Assume that imports, aggregate demand, and import prices are growing at constant rates along the steady-state path. Then, $\Delta \ln \bar{M}_{t}-\sum_{k} \Delta\left(\beta_{k, t} \ln \bar{D}_{k, t}\right)+\beta_{P} \Delta \ln \bar{P}_{M, t}$ is a constant, which we denote $\delta$, and we can rewrite equation (10) as:

$$
\Delta \ln M_{t} \approx \delta+\sum_{k} \Delta\left(\beta_{k, t} \ln D_{k, t}\right)+\beta_{P} \Delta \ln P_{M, t}
$$

To a first order, we reduced import growth to an increasing function of aggregate demand growth and a decreasing function of growth in import prices.

Next, assume that there exists a $\beta_{D}>0$ such that $\beta_{k, t}=\beta_{D} \omega_{k, t}$. Then,

$$
\Delta \ln M_{t} \approx \delta+\beta_{D} \sum_{k} \Delta\left(\omega_{k, t} \ln D_{k, t}\right)+\beta_{P} \Delta \ln P_{M, t}
$$

Finally, letting $k=C, G, I, X ; D_{C} \equiv C, D_{G} \equiv G, D_{I} \equiv I, D_{X} \equiv X$, and recalling the definition $I A D_{t} \equiv C_{t}^{\omega_{C, t}} G_{t}^{\omega_{G, t}} I_{t}^{\omega_{I, t}} X_{t}^{\omega_{X, t}}$ returns:

$$
\Delta \ln M_{t} \approx \delta+\beta_{D} \Delta \ln I A D_{t}+\beta_{P} \Delta \ln P_{M, t}
$$

This - or, more precisely, its stochastic version - is the benchmark regression equation of the same form as (3), with $I A D$ as the correct measure of aggregate demand, and with unrestricted aggregate demand elasticity $\beta_{D}{ }^{26}$

In principle, one could econometrically estimate the individual coefficients $\beta_{k, t}$ by estimating

$$
\Delta \ln M_{t}=\delta+\sum_{k} \Delta\left(\beta_{k, t} \ln D_{k, t}\right)+\beta_{P} \Delta \ln P_{M, t}+\varepsilon_{t},
$$

where $\varepsilon_{t}$ is the error term, at the cost of degrees of freedom. Our approach is to impose the coefficients $\omega_{k, t}$ from the Input-Output tables (subject to the normalization $\sum_{k} \omega_{k, t}=1$ ) and use the constructed aggregate variable $I A D_{t}$ in the stochastic version of (11), identifying the common constant coefficient $\beta_{D}$.

\footnotetext{
${ }^{25}$ Note that the regression equations based on C.E.S. demand also abstract from a direct effect of changes in factor endowments.

${ }^{26}$ As Feenstra (2003a, Ch. 3) notes, the approach we followed - treating exports and imports as an output and input, respectively, in the production process, and defining exports and imports independently from consumption-is sensible if exports are differentiated from domestic goods and imports are mainly intermediates. Both are empirically plausible assumptions.
} 


\subsection{Translog Import Function}

An alternative to the approach above would be to assume instead that the import function $M=$ $-V_{P_{M}}\left(D, P_{M}, F\right)$ is directly described by the translog function:

$$
\begin{aligned}
\ln M & =\alpha+\sum_{k} \beta_{k} \ln D_{k}+\beta_{P} \ln P_{M}+\sum_{f} \beta_{f} \ln F_{f} \\
& +\frac{1}{2} \sum_{k} \sum_{j} \lambda_{k j} \ln D_{k} \ln D_{j}+\frac{1}{2} \lambda_{P}^{2}\left(\ln P_{M}\right)^{2}+\frac{1}{2} \sum_{f} \sum_{h} \lambda_{f h} \ln F_{f} \ln F_{h} \\
& +\sum_{k} \sum_{f} \phi_{k f} \ln D_{k} \ln F_{f}+\ln P_{M} \sum_{k} \phi_{k} \ln D_{k}+\ln P_{M} \sum_{f} \phi_{f} \ln F_{f},
\end{aligned}
$$

where $\beta_{P}<0 .{ }^{27}$

In this case, the $I A D$-based regression equation essentially follows from first-differencing (12) under the assumption that second-order terms and factor endowments are constant over time. Introducing time indexes and allowing for time variation in the coefficients $\beta_{k}$, this yields:

$$
\Delta \ln M_{t}=\sum_{k} \Delta\left(\beta_{k, t} \ln D_{k, t}\right)+\beta_{P} \Delta \ln P_{M}
$$

Assuming next that $\beta_{k, t}=\beta_{D} \omega_{k, t}$ and proceeding as in the case of the translog GDP function, we obtain:

$$
\Delta \ln M_{t}=\beta_{D} \Delta \ln I A D_{t}+\beta_{P} \Delta \ln P_{M, t} .
$$

Except for the constant included in the regression and the error term, this is again the benchmark regression equation with $I A D$ as the correct measure of aggregate demand in import determination.

The advantage of this approach to obtaining the regression equation is that it does not rely on the approximations used with the translog GDP function and, therefore, it is not restricted to small perturbations around the steady-state path (which certainly do not describe the 2008-09 collapse). On the other hand, the assumption of a translog GDP function is more conventional in the literature. Importantly, though, both approaches provide a justification for the same import demand and regression equation. As we shall show below, using $I A D$ in this standard regression equation outperforms the traditional alternatives.

\section{Empirical Analysis}

The objective of this section is to test empirically the ability of the new import intensity-adjusted measure of demand to explain the dynamics of import flows. To this aim, we first investigate the overall performance of regressions of the form (11) against other specifications using standard measures of aggregate demand. We then explicitly look at the Great Trade Collapse episode of 200809 to understand whether the fall in world trade during the GTC is still largely unexplained once

\footnotetext{
${ }^{27}$ We again omit parameter restrictions we do not rely on below.
} 
the import intensity of aggregate demand components is taken into account (which would call for other factors as primary explanations of the GTC). Finally, we assess the performance of our new measure of aggregate demand at tracking import flows over different phases of the business cycle, comparing it with the performance of the standard GDP specification, with an eye to addressing the broader Houthakker-Magee puzzle.

Results build on a dataset of 18 OECD countries, repeated here for the reader's convenience: Australia, Canada, Denmark, Finland, France, Germany, Italy, Japan, Korea, Netherlands, Norway, New Zealand, Portugal, Spain, Sweden, Switzerland, the United Kingdom, and the United States. The data on imports and exports of goods and services, GDP, private and government consumption, investment, all in volume, and the series of import prices come from the OECD Economic Outlook database. $^{28}$ The time series are at quarterly frequency, and the estimation is performed over the period 1985Q1-2010Q2. We construct relative import prices by dividing the series of import prices of goods and services for each country by the respective GDP deflator.

\subsection{Panel Estimation Results}

We start by estimating a simple, standard equation for imports. In the regression, motivated by theory, the quarterly growth of real imports for each country $c, \Delta \ln M_{c, t}$, depends on contemporaneous values of the quarterly growth of aggregate demand, $\Delta \ln D_{c, t}$, and the quarterly growth of relative import prices, $\Delta \ln P_{M, c, t}$, as well as country dummies $\delta_{c}$ :

$$
\Delta \ln M_{c, t}=\delta_{c}+\beta_{D} \Delta \ln D_{c, t}+\beta_{P} \Delta \ln P_{M, c, t}+\varepsilon_{c, t}
$$

In the analysis that follows, we compare three measures of aggregate demand: Two are standard measures, where either GDP or domestic demand, DD (computed as the sum of private and government consumption and investment), are used as measures of $D$, and the third is the new import intensity-adjusted measure of demand, $I A D$. We also consider an alternative specification of the equation, where import growth is a function also of its own lags and lags of the explanatory variables to allow for richer dynamics: ${ }^{29}$

$$
\Delta \ln M_{c, t}=\delta_{c}+\sum_{l=0}^{L} \beta_{D, l} \Delta \ln D_{c, t-l}+\sum_{l=0}^{L} \beta_{P, l} \Delta \ln P_{M, c, t-l}+\sum_{l=1}^{L} \beta_{M, l} \Delta \ln M_{c, t-l}+\varepsilon_{c, t}
$$

We estimate panel regressions of the type (14) and (15) using country-specific fixed effects and robust variance-covariance matrix estimates. ${ }^{30}$ Table 3 presents the in-sample results of the 6 speci-

\footnotetext{
${ }^{28}$ We use time series on gross fixed capital formation (GFCF) to proxy for investment in the empirical exercise. This is consistent with the fact that we use the import content of GFCF computed from the OECD I-O tables to construct $I A D$. Although we are aware that investment does not coincide with GFCF, we will use the term investment instead of GFCF in the rest of the paper.

${ }^{29}$ We considered $L=1$ in our preferred specification.

${ }^{30}$ As a robustness check we also performed the same regressions using fixed weights (at the 2005 values) instead of time-varying weights in constructing $I A D$ to assess the extent to which using changing weights affects our results. The
} 
fications just described for the full set of 18 countries and the G7 (Canada, France, Germany, Italy, Japan, the UK, and the U.S.) for the entire sample period. Estimation results show that the regression using $I A D$ is noticeably superior to those using GDP or DD in terms of fit, and this applies both to the full set of countries and the sub-set of G7 countries. Including lags of the dependent and independent variables improves the fit marginally and does not reveal substantial changes in the elasticity point estimates, especially when using $I A D$ as demand variable. The ranking of the three measures of $D$ also remains unchanged. ${ }^{31}$

Figure 7 shows actual and fitted values of real import growth for a subsample of countries ${ }^{32}$, where the fitted values are obtained by estimating the panel regression (15) using respectively $I A D$, GDP, and DD as demand variables. The superiority of $I A D$ in tracking import growth against the alternatives stands out clearly from the figure, especially in periods of large falls in imports, such as the Great Trade Collapse of 2008-09.

\subsection{The Composition of Demand and the Great Trade Collapse}

Figures 8 illustrates exactly how much of the fall in imports observed during 2008Q4 and 2009Q1 the three aggregate demand specifications are able to account for on average and for each individual country (panel A and B refer to the panel regression (15) for all 18 countries, whereas panel C and D to the same regression performed for the G7 only): The blue bar in the "Total" part of each diagram shows the actual fall in aggregate imports in the 18 countries $^{33}$ together with the predicted aggregate fall using IAD (black bars), GDP (red bars), and DD (green bars), respectively. In particular, the weighted average of real imports in our sample of countries fell by $5.6 \%$ in 2008Q4 and 9.3\% in 2009Q1, on a quarterly basis. Using $I A D$ as explanatory variable captures $67 \%$ and $63 \%$ of the fall in aggregate imports in 2008Q4 and 2009Q1, respectively, while only $41 \%$ and $29 \%$ is explained by the GDP-based specification. Results for the G7 are even more striking: On average, using IAD explains $94 \%$ and $85 \%$ of the average fall in imports in the G7, against $61 \%$ and $51 \%$ when GDP is used. In panel C and D, an additional (orange) bar is included for each country, corresponding to the predictions of the $I A D$ specification controlling also for changes in inventories. ${ }^{34}$ As shown by the

\footnotetext{
results of this exercise, which we do not show here for brevity, show very little change in the coefficient estimates and in sample fit of the IAD specification. (Details are available upon request.) This shows that the superiority of IAD that we document below relies on the ability of our new measure of demand to capture the dynamics of the different demand components and not on the time-variation of the aggregating weights.

${ }^{31}$ Notice that, in all specifications, we add two dummy variables to capture two episodes of erratic movements in trade in the UK in 2006Q1 and 2006Q3. Concerning these quarters the UK Office for National Statistics said: "Erratic and large movements in the level of trade associated with VAT Missing Trader Intra Community (MTIC) fraud have made it especially difficult to interpret movements in imports and exports of goods." The inclusion of such dummies does not change the essence of the results.

${ }^{32}$ The U.S., the UK, Germany, France, Japan, Canada, Italy, and Spain. We do not report the results for the other countries to save space, but they are available upon request.

${ }^{33}$ To construct the aggregate values of import growth, we used the respective average import shares of the countries between 2000 and 2009 .

${ }^{34}$ In particular, we estimate equation (15) using $I A D$ as demand variable and adding as a control variable the changes in inventories as a percentage of GDP. For this exercise we used the time series of "change in stocks" and GDP at current prices from the OECD Main Economic Indicator Database. The lack of long spans of data for some countries
} 
orange bars, including changes in inventories helps improve the fit of the model: On average, using $I A D$ and controlling for changes in inventories explains $99 \%$ and $93 \%$ of the average fall in imports in the G7 in 2008Q4 and 2009Q1, respectively.

The specification using $I A D$ allows us to go one step further in investigating the relation between the composition of demand and the GTC. Using the estimated coefficients from regression (15), we can decompose import growth for each country in the panel and compute the individual contribution of the four $I A D$ components $(C, I, X$, and $G)$, as well as $P_{M}$, in explaining import fluctuations. This allows us to disentangle, for instance, the relative importance of each demand component in driving the fall in imports during the GTC.

Table 4 shows such a decomposition for 2009Q1, which corresponds to the trough in trade series during the recent global crisis. The second column in the table reports quarterly import growth in 2009Q1 for the 18 countries in the panel; Columns 3 to 8 report the percentage of the fall in imports explained by the explanatory variables $I A D$ and $P_{M}$ in equation (15) and by each demand component in $I A D$ (notice that the sum of the contributions of $C, I, X$, and $G$ is equal to the contribution of $I A D)$. The last column shows the percentage of the fall in imports explained by GDP from the regression using GDP as demand measure.

Several results are worth noting: First, the percentage of import growth explained by $I A D$ alone is in general very high, sometimes close to $100 \%$, and, in most of the cases, much higher than the percentage explained by GDP alone (in the cases of Germany and Sweden, however, both specifications produce a larger-than-observed fall in imports, with the specification using GDP doing slightly better than the $I A D$ one). Second, the contribution of $P_{M}$ is negative for most of the countries, meaning that relative import prices generally decreased in 2009Q1, hence, contributing an increase rather than a decrease in imports over the same quarter (remember that the coefficient of $P_{M}$ in Table 3 is negative).

Finally, looking at the individual demand components, two main facts emerge: First, private and government consumption growth contribute only marginally to explaining the fall in imports in 2009Q1, the former explaining at most about $10 \%$ of it in a few countries, such as Denmark, the UK, and the Netherlands, and the latter explaining an even lower percentage (and often implying an increase rather than a decrease in imports as a result of the fact that government consumption was increasing in most of the countries following the implementation of counter-cyclical fiscal policies). Second, while investment and exports indeed explain most of the fall in imports, the main driver of the fall varies substantially across countries, making it possible to identify countries that experienced an "export-driven" or an "investment-driven" import collapse. The U.S., Norway, Sweden, and New Zealand are among the countries that experienced an "investment-driven" import collapse, although the percentage of the import fall explained by exports is also high for some of them. Japan, France,

in our sample makes it impossible to perform the same exercise for the entire panel of 18 countries. The results of this exercise are not shown here for brevity, but they are available upon request. 
Italy, Spain, Portugal, Belgium, Finland, and Korea instead experienced an "export-driven" import collapse. Finally, in some countries, such as the UK, Canada, Germany, and the Netherlands, both components of demand played roles of more similar magnitude in explaining the fall in imports. ${ }^{35}$

To summarize, according to our investigation, there is no major "puzzle" in the magnitude of the fall in world trade observed during the recent financial crisis: Trade fell mostly because demand crashed globally and did so particularly in its most import-intensive component-investment. Moreover, the strong relationship between exports and imports in each country, linked to the increased internationalization of production and the strong dependence of the tradable sector on imported inputs, contributed to the simultaneity and unprecedented severity of the trade collapse. Our approach and results confirm Marquez's (1999) argument that using standard measures of aggregate demand, such as GDP or domestic demand, in trade equations may be misleading, and more so in periods in which the more import-intensive components of aggregate demand (i.e., investment and exports) fluctuate much more than the others, such as the 2008-09 crisis.

\subsection{Trade Elasticities over the Business Cycle: Toward a Solution to the Houthakker- Magee Puzzle}

Since the specification using $I A D$ performs well in explaining the 2008-09 Great Trade Collapse, it is important to understand whether the superiority of $I A D$ against standard alternatives shown in Table 3 comes from a better fit only during recession periods, when highly import-intensive demand components tend to fall on average more than the components that are relatively less import-intensive (as shown in Figure 6), or survives also when those periods are taken out of the sample. This is a relevant question, since only in the second case we would be able to conclude that the new measure of demand is in fact superior to standard measures and should be preferred in empirical work aimed at estimating trade elasticities. Moreover, since not all recessions are crises and not all crises are global, such as the 2008-09 one, we perform two alternative estimations for the recession periods, one in which we exclude the recent global crisis and one where we include it.

This exercise also allows us to look more carefully at the values of the elasticity of imports to aggregate demand over the business cycle, with an eye to addressing the well-known HouthakkerMagee puzzle. In Section 4, we have provided a theoretical foundation for a (log) import demand equation that is consistent with the traditional regression equation (14) (which, in turn, is the foundation for regression (15) in the empirical literature), and does not restrict the elasticity of imports to aggregate demand to be one. However, as discussed above, a demand system that does not restrict the coefficient of aggregate demand in the import equation to one does not in itself imply resolution of the economic puzzle that a coefficient significantly above one can derail sustainability. ${ }^{36}$

\footnotetext{
${ }^{35}$ Results for 2008Q4, which we do not show here to save space, are broadly similar and provide the same country classification.

${ }^{36}$ This represents a puzzle because it implies that, to prevent the trade balance from permanently moving into deficit, the real exchange rate should permanently depreciate over time (this is also under the condition that foreign
} 
Table 5 shows the result of the regressions (14) and (15) estimated separately for three different data samples, one looking only at recessions and excluding the 2008-09 crisis, labeled as "recessions" in the table, one looking at all recessions including the 2008-09 crisis, labeled as "GTC", and one looking only at "expansion" periods. ${ }^{37}$ We compare here the results from the equation using our new import intensity-adjusted measure of demand and the specification using GDP, this latter being in general the preferred measure in the literature estimating import elasticities. In the bottom panel of Table 5, which shows results from regression equation (15), we report directly the sum of the coefficients on contemporaneous and lagged aggregate demand to facilitate the comparison between the two specifications. Several results are worth mentioning. First, both specifications do better at estimating real import growth during recession times, i.e., in periods when the fall in demand is particularly crucial to explain the behavior of trade. Second, the regression using $I A D$ outperforms the GDP one during both phases of the cycle in terms of goodness of fit - the improvement from using $I A D$ being even larger in the expansionary phases of the cycle. This shows that the results in Table 3 are not driven only by extreme events, but they apply to the entire estimation period. Third, the elasticity of imports to aggregate demand generally varies between recessions and expansions, with some important distinctions to be made.

Starting with the results of "recessions" and "expansions" only (hence, excluding the GTC episode): The import elasticity to GDP doubles during recessions and is close to 3 when one lag of the exogenous variables is included in the regression. Instead, when $I A D$ is used as aggregate demand measure, the elasticity of imports to aggregate demand is remarkably stable across expansions and recessions. It is exactly equal to one in the regression without lags and close to 1.5 when one lag of $I A D$ is added. ${ }^{38}$ These findings corroborate the idea that using GDP as demand measure in trade equations may be misleading as it delivers highly volatile estimates of demand elasticities that may indicate the presence of structural breaks even when this is not the case. Moreover, these results suggest that the Houthakker-Magee puzzle, which is generally found in estimation of import equations using GDP as measure of aggregate demand, may be driven by the inclusion of few but highly volatile observations in the estimation sample, i.e., by the inclusion of recession episodes. ${ }^{39}$ Our new measure of demand, instead, by taking into account the different import contents of demand components, delivers elasticities that are lower in magnitude and more stable over the cycle, making a significant step toward the solution of the Houthakker-Magee puzzle. ${ }^{40}$

and domestic output grow at similar rates). Another puzzling implication of having a demand elasticity above one is that output should be completely imported in the long run, barring a permanent depreciating trend.

${ }^{37}$ As in the previous section, recessions are defined as two consecutive quarters of negative real GDP growth. We present results for the full set of countries. Results for the G7 are very similar and are available upon request.

${ }^{38}$ As a corollary, the $I A D$ specification also provides higher (in absolute value) and more significant estimates for the elasticities to import prices, which is a promising result as few papers find a large and significant role for relative prices in trade equations.

${ }^{39}$ In their 1969 article, Houthakker and Magee use GNP at constant prices to compute import elasticities. Other studies have used either GNP or GDP to estimate the elasticity of imports to aggregate demand for the U.S. and other advanced economies (e.g., see Hooper, Johnson, and Marquez, 2000, and the literature reviewed therein).

${ }^{40}$ The empirical literature estimating import elasticities generally distinguishes between short-run and long-run elas- 
Turning to the recession sample this time including the 2008-09 crisis, we observe an even stronger increase of the elasticity of imports to GDP compared to expansionary phases - the contemporaneous elasticity increases by a factor of 4 against a twofold increase when the GTC is excluded. In the case of $I A D$, we also observe an increase of the import elasticity, although much lower than in the GDP case, and a substantial increase of the in-sample fit. The increase in the elasticity estimates in both specifications suggests that the 2008-09 global crisis was indeed an exceptional event. In particular, results in Table 5 suggest that nonlinearities in the relation between imports and aggregate demand still persist when $I A D$ is used as measure of aggregate demand. This may be due to the role of other factors not accounted for in our simple model of imports, such as financial constraints, the analysis of which is beyond the scope of this paper. However, our simple model is enough to explain most of the GTC episode, as shown in Section 5.2, and to reduce dramatically the elasticity difference between different phases of the cycle.

To summarize, although a direct comparison with other models is not possible, the results using $I A D$ as demand variable go in the same direction of other papers that found lower import elasticities to measures of aggregate demand once import equations are corrected for other factors, such as vertical integration or aggregation bias. Cardarelli and Rebucci (2007), for instance, find that once exports of intermediate products are added in the U.S. import equation to account for vertical integration, the resulting GDP elasticity of imports drops significantly and becomes lower than one. A similar result holds in Bussière, Chudik, and Sestieri (2009) in the context of a global VAR where exports enter in the import cointegration relation. Our approach is in principle more complete, as we do not correct only for vertical integration, but also for the import content of different demand components that is not taken into account when using GDP. Moreover, this approach has the advantage of using a single statistic, the import intensity-adjusted measure of demand, delivering a single demand coefficient of easier interpretation.

\section{Conclusion}

This paper proposed a new methodology for the estimation of trade elasticities, based on an import intensity-adjusted measure of aggregate demand. While standard empirical trade models typically use GDP (or domestic demand) as measure of aggregate demand, we argue that there is value added in giving different weights to the components of GDP, which typically have very different import intensities. In particular, the analysis of the new OECD Input-Output tables shows that, in general, investment is significantly more import intensive than private consumption, which in turn is more import intensive than government spending. In addition, we also find that exports are very import intensive.

ticities, the latter generally preferred in debates on the sustainability of the current account to which the HouthakkerMagee puzzle is related. Here, we compute and discuss only short-run elasticities, the correct model specification to estimate long-run elasticities being beyond the scope of this paper. 
Carefully disentangling the effects of investment, private and government consumption, and exports turns out to improve the goodness of fit of the model significantly, and it is especially important in the context of the 2008-09 crisis, during which these different components of aggregate demand evolved very differently. In particular, investment and exports decreased most significantly over this period, whereas government spending remained robust, supported largely by the fiscal packages put in place by governments in response to the crisis. Recognizing that investment and exports are more import intensive than private and government consumption helps explain why regressions using standard measures of aggregate demand that do not account for differences in import intensity typically underestimate the fall in trade that took place in 2008-09. Moreover, the high import intensity of exports contributes to explaining the synchronicity of the trade collapse across countries. We reported key stylized facts on these developments, put also in historical perspective, and provided a theoretical foundation and econometric evidence in support of our novel measure of demand. We showed that using the import intensity-adjusted measure of demand proposed in this paper can significantly enhance the performance of empirical trade models, helping resolve new and long-standing questions in international economics. 


\section{References}

Ahn, J, M. Amity, and D. E. Weinstein (2011): "Trade Finance and the Great Trade Collapse," American Economic Review Papers and Proceedings 101: 298-302.

Alessandria, G., J. P. Kaboski, and V. Midrigan (2010): "The Great Trade Collapse of 2008-09: An Inventory Adjustment?," IMF Economic Review 58: 254-294.

Amity, M., and D. E. Weinstein (2011): "Exports and Financial Shocks," Quarterly Journal of Economics.126: 1841-1877

Baldwin, R. (2009): "The Great Trade Collapse: Causes, Consequences and Prospects," VoxEU.org Ebook, November 27, 2009.

Bems, R., R. C. Johnson, and K.-M. Yi (2010): "Demand Spillovers and the Collapse of Trade in the Global Recession," IMF Economic Review 58: 295-326.

Bénassy-Quéré, A, Y. Decreux, L. Fontagné and D. Khoudour-Castéras (2009): "Economic Crisis and Global Supply Chain,” CEPII Document de Travail 2009-15.

Bergin, P. R., and R. C. Feenstra (2000): "Staggered Price Setting and Endogenous Persistence," Journal of Monetary Economics 45: 657-680.

Bergin, P. R., and R. C. Feenstra (2001): "Pricing-to-Market, Staggered Contracts, and Real Exchange Rate Persistence," Journal of International Economics 54: 333-359.

Bilbiie, F. O., F. Ghironi, and M. J. Melitz (2007): "Endogenous Entry, Product Variety, and Business Cycles," NBER Working Paper 13646.

Bussière, M., A. Chudik, and G. Sestieri (2009): "Modeling Global Trade: Results from a GVAR Model," ECB Working Paper 1087.

Cardarelli, R., and A. Rebucci (2007): "Exchange Rates and the Adjustment of External Imbalances," in World Economic Outlook, Chapter 3, International Monetary Fund, April.

Chor, D., and K. Manova (2011): "Off the Cliff and Back? Credit Conditions and International Trade during the Global Financial Crisis," Journal of International Economics, forthcoming.

Corsetti, G., L. Dedola, and S. Leduc (2008): "International Risk-Sharing and the Transmission of Productivity Shocks," Review of Economic Studies 75: 443-473.

De Backer, K., and N. Yamano (2007): "The Measurement of Globalisation using International Input-Output Tables," OECD Science, Technology and Industry Working Paper 2007/8, OECD, Directorate for Science, Technology and Industry. 
Eaton, J., S. Kortum, B. Neiman, and J. Romalis (2011): "Trade and the Global Recession," NBER Working Paper 16666.

Erceg, C., L. Guerrieri, and C. Gust (2006): "Trade Adjustment and the Composition of Trade," International Finance Discussion Paper 2006-859, Board of Governors of the Federal Reserve System.

Feenstra, R. C. (1994): "New Product Varieties and the Measurement of International Prices," The American Economic Review 84: 157-77.

Feenstra, R. C. (2003a): Advanced International Trade: Theory and Evidence, Princeton University.Press, Princeton, NJ.

Feenstra, R. C. (2003b): "A Homothetic Utility Function for Monopolistic Competition Models, without Constant Price Elasticity," Economics Letters 78: 79-86.

Feenstra, R. C., Z. Li, and M. Yu. (2010): "Exports and Credit Constraints under Private Information: Theory and Evidence from China," NBER Working Paper 16940.

Ghironi, F., and M. J. Melitz (2005): "International Trade and Macroeconomic Dynamics with Heterogeneous Firms," Quarterly Journal of Economics 120: 865-915.

Guo, D., C. Webb, and N. Yamano (2009): "Towards Harmonised Bilateral Trade Data for InterCountry Input-Output Analyses: Statistical Issues," OECD Science, Technology and Industry Working Paper 2009/4, OECD, Directorate for Science, Technology and Industry.

Harrigan, J. (1997): "Technology, Factor Supplies, and International Specialization: Estimating the Neoclassical Model," American Economic Review 87: 475-494.

Hooper, P., K. Johnson, and J. Marquez (2000): "Trade Elasticities for the G-7 Countries," Princeton Studies in International Economics 87.

Houthakker, H. S., and S. P. Magee (1969): "Income and Price Elasticities in World Trade," Review of Economics and Statistics 51: 111-125.

Hummels, D., J. Ishii, and K.-M. Yi, (2001): "The Nature and Growth of Vertical Specialization in World Trade," Journal of International Economics 54: 75-96.

International Monetary Fund (2010): World Economic Outlook, Chapter 4, "Do Financial Crises Have Lasting Effects on Trade?," October 2010.

Johnson, R.C., and G. Noguera (2011): "Accounting for Intermediates: Production Sharing and Trade in Value Added," Journal of International Economics, forthcoming.

Kee, H. L., A. Nicita, and M. Olarreaga (2008): "Import Demand Elasticities and Trade Distortions," Review of Economics and Statistics 90: 666-682. 
Kohli, U. (1978): "A Gross National Product Function and the Derived Demand for Imports and Supply of Exports," Canadian Journal of Economics 11: 167-182.

Kohli, U. (1990a): "Price and Quantity Elasticities in U.S. Foreign Trade," Economics Letters 33: $277-281$.

Kohli, U. (1990b): "Growth Accounting in the Open Economy: Parametric and Nonparametric Estimates," Journal of Economic and Social Measurement 16: 125-136.

Kohli, U. (1993): "GNP Growth Accounting in the Open Economy: Parametric and Nonparametric Estimates for Switzerland," Swiss Journal of Economics and Statistics 129: 601-615.

Leibovici, F., and M. E. Waugh (2011): "International Trade and Intertemporal Substitution," unpublished manuscript, New York University

Levchenko, A., L. Lewis, and L. Tesar (2010): "The Collapse of International Trade in 2008-9: In Search of the Missing Gun," IMF Economic Review 58: 214-253.

Levchenko, A., L. Lewis, and L. Tesar (2011): "The 'Collapse in Quality' Hypothesis," American Economic Review Papers and Proceedings 101: 293-297.

Mann, C. L., and K. Plück (2005): "The U.S. Trade Deficit: A Disaggregated Perspective," Working Paper Series WP05-11, Peterson Institute for International Economics.

Marquez, J. R. (1999): "Long-Period Trade Elasticities for Canada, Japan, and the United States," Review of International Economics 7: 102-16.

Marquez, J. R. (2002): Estimating Trade Elasticities, Kluwer Academic Publisher, Dordrecht, The Netherlands.

Organization for Economic Cooperation and Development (2011): OECD Science, Technology and Industry Scoreboard 2011, http://dx.doi.org/10.1787/sti_scoreboard-2011-en.

Rodríguez-López, J.-A. (2011): "Prices and Exchange Rates: A Theory of Disconnect," Review of Economic Studies 78: 1135-1177.

Sundararajan, V., and S. Thakur (1976): "Input-Output Approach to Import Demand Functions: Experiments with Korean Data," IMF Staff Papers 23: 674-698.

Yamano, N., and N. Ahmad (2006): "The OECD Input-Output Database: 2006 Edition," OECD Science, Technology and Industry Working Paper 2006/8, OECD, Directorate for Science, Technology and Industry. 
Figure 1: Recent developments and projections in world trade and output (volumes)

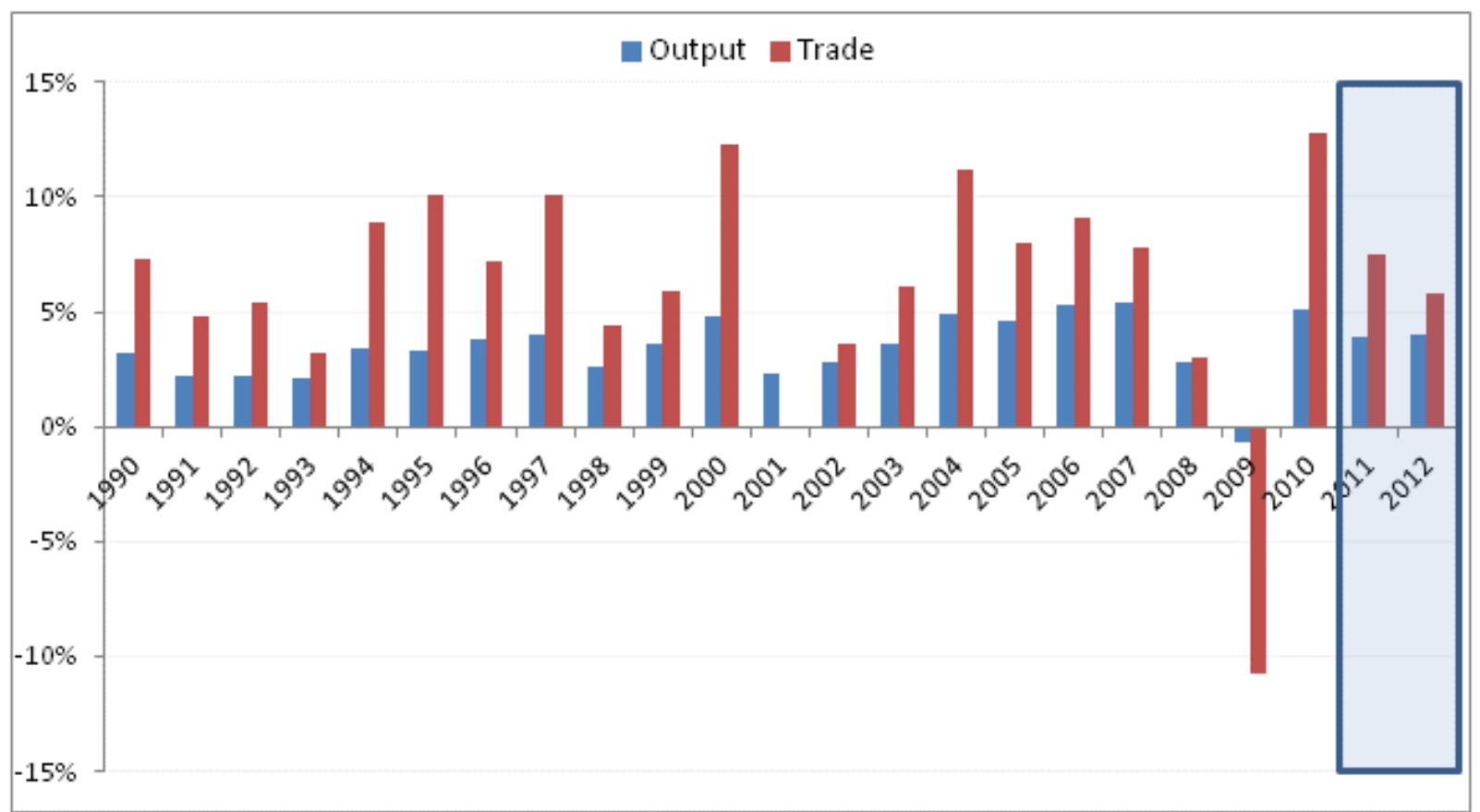

Source: IMF World Economic Outlook September 2011.

Figure 2: Growth rate of real imports in 2008Q4 and 2009Q1, q-o-q growth rates

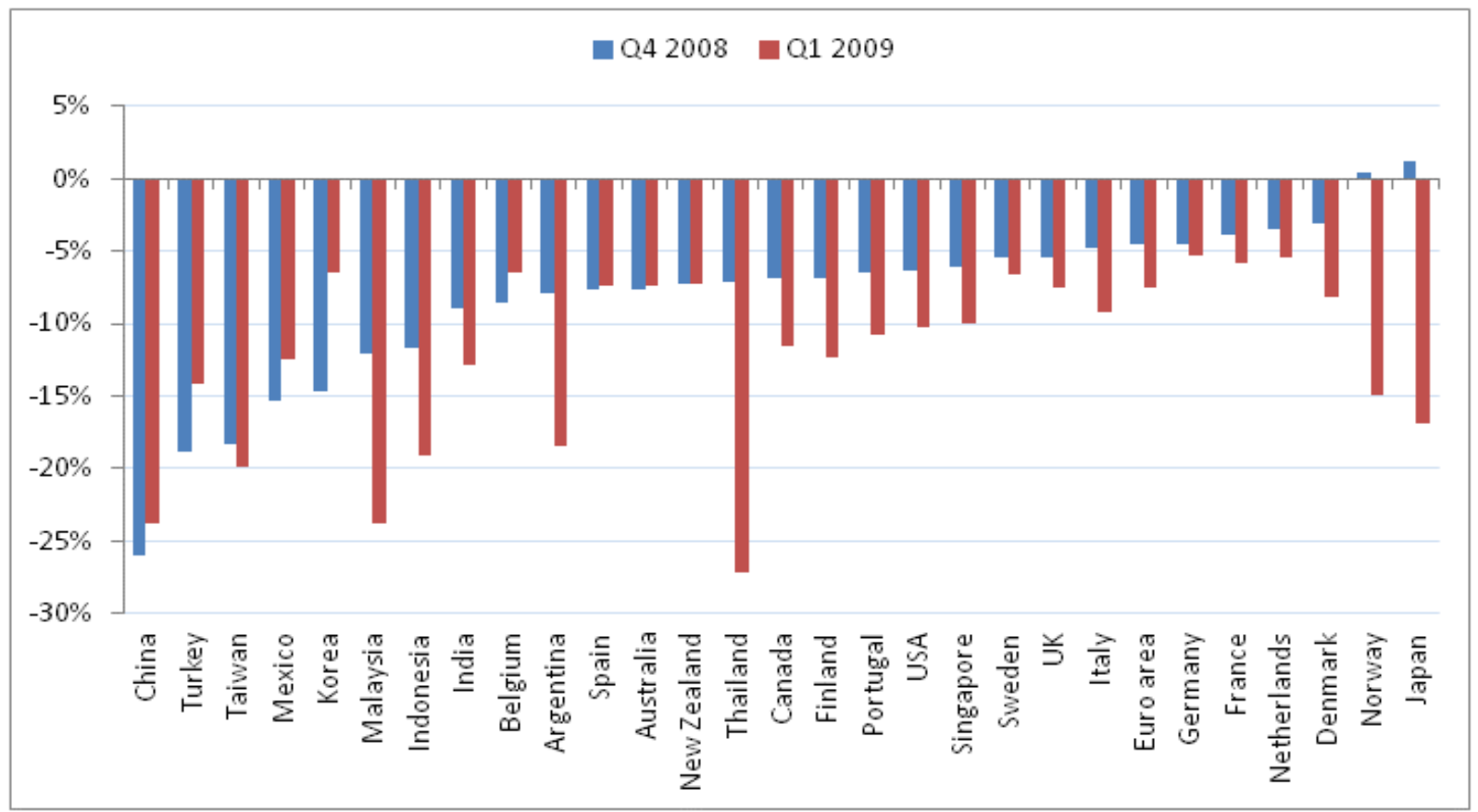

Source: OECD Economic Outlook. 
Figure 3: OECD Input-Output tables of Total, Domestic and Import transactions

\begin{tabular}{|c|c|c|c|c|c|c|c|}
\hline \multirow{2}{*}{ Total } & \multicolumn{2}{|c|}{ Intermediate } & \multicolumn{5}{|c|}{ Final demand } \\
\hline & Ind 1 & $\operatorname{lnd} 2$ & PC & GC & GFCF & Exports & Imports \\
\hline \multicolumn{8}{|l|}{ Ind 1} \\
\hline \multicolumn{8}{|l|}{ Ind 2} \\
\hline \multicolumn{8}{|l|}{ VA } \\
\hline Output & & & & & & & \\
\hline
\end{tabular}

\begin{tabular}{|c|c|c|c|c|c|c|c|}
\hline \multirow{2}{*}{ Domestic } & \multicolumn{2}{|c|}{ Intermediate } & \multicolumn{5}{|c|}{ Final demand } \\
\hline & Ind 1 & Ind 2 & $P C$ & GC & GFCF & Exports & Imports \\
\hline Ind 1 & \multirow{2}{*}{\multicolumn{2}{|c|}{$Z^{d}$}} & \multirow{2}{*}{\multicolumn{5}{|c|}{$F^{d}$}} \\
\hline Ind 2 & & & & & & & \\
\hline \multicolumn{8}{|l|}{ Imports } \\
\hline \multicolumn{8}{|l|}{ VA } \\
\hline Output & & & & & & & \\
\hline
\end{tabular}

\begin{tabular}{|l|c|c|c|c|c|c|c|}
\hline \multirow{2}{*}{ Import } & \multicolumn{2}{|c|}{ Intermediate } & \multicolumn{5}{c|}{ Final demand } \\
\cline { 2 - 7 } & Ind 1 & Ind 2 & PC & GC & GFCF & Exports & Imports \\
\hline Ind 1 & \multicolumn{2}{|c|}{$\mathrm{Z}^{\mathrm{m}}$} & \multicolumn{5}{|c|}{$\mathrm{F}^{\mathrm{m}}$} \\
\hline Ind 2 & \multicolumn{2}{|c|}{} \\
\hline
\end{tabular}

PC: Private consumption by households, GC: Government consumption, GFCF: Gross fixed capital formation, VA: value added $A^{d}=Z^{d} /$ Output; $A^{m}=Z^{m} /$ Output 
Figure 4: Import contents of main GDP components

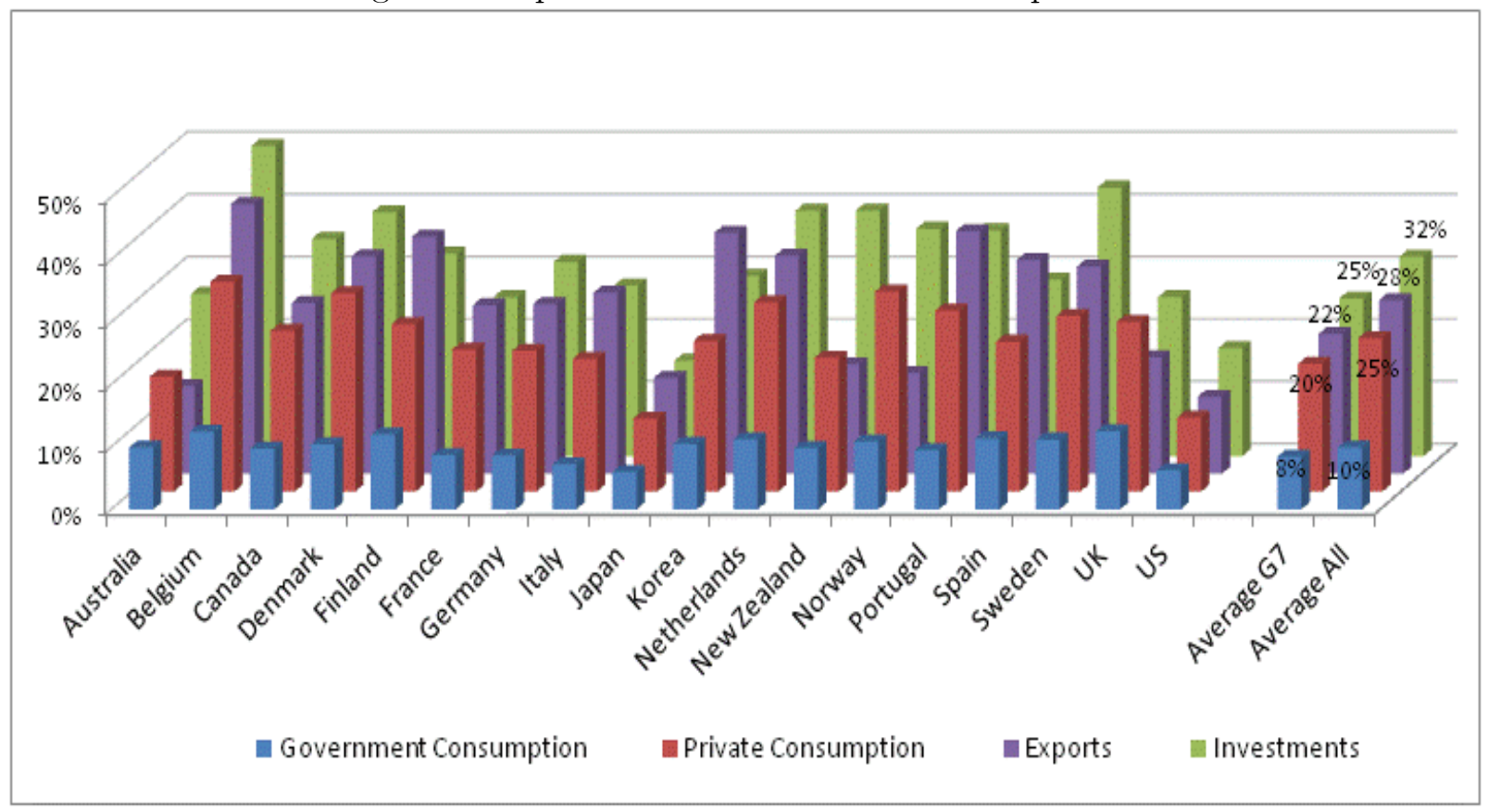

Source: OECD OECD Input-Output Tables and authors' calculations.

Figure 5: Short-term correlations between imports and main GDP components

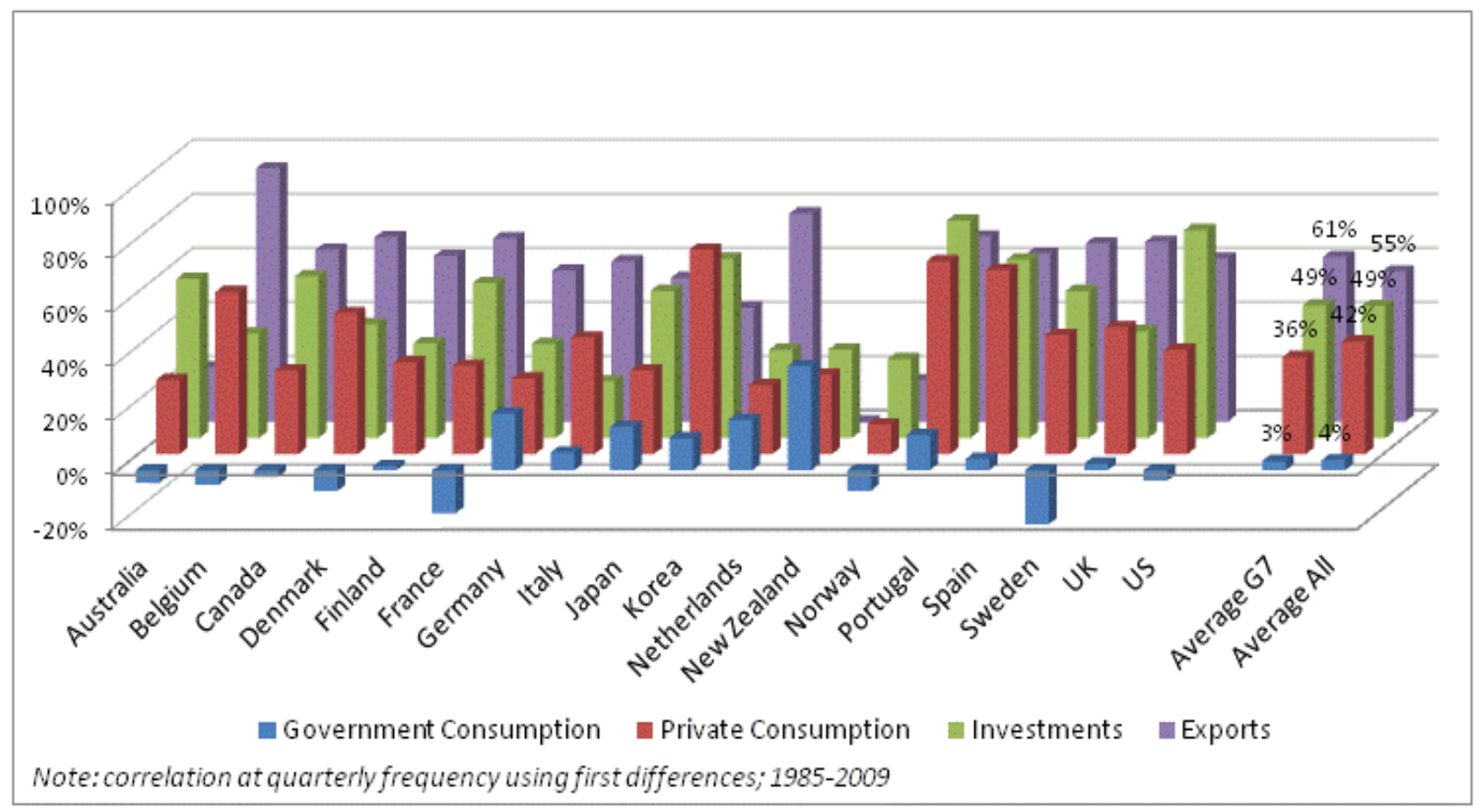

Source: OECD and authors' calculations. 

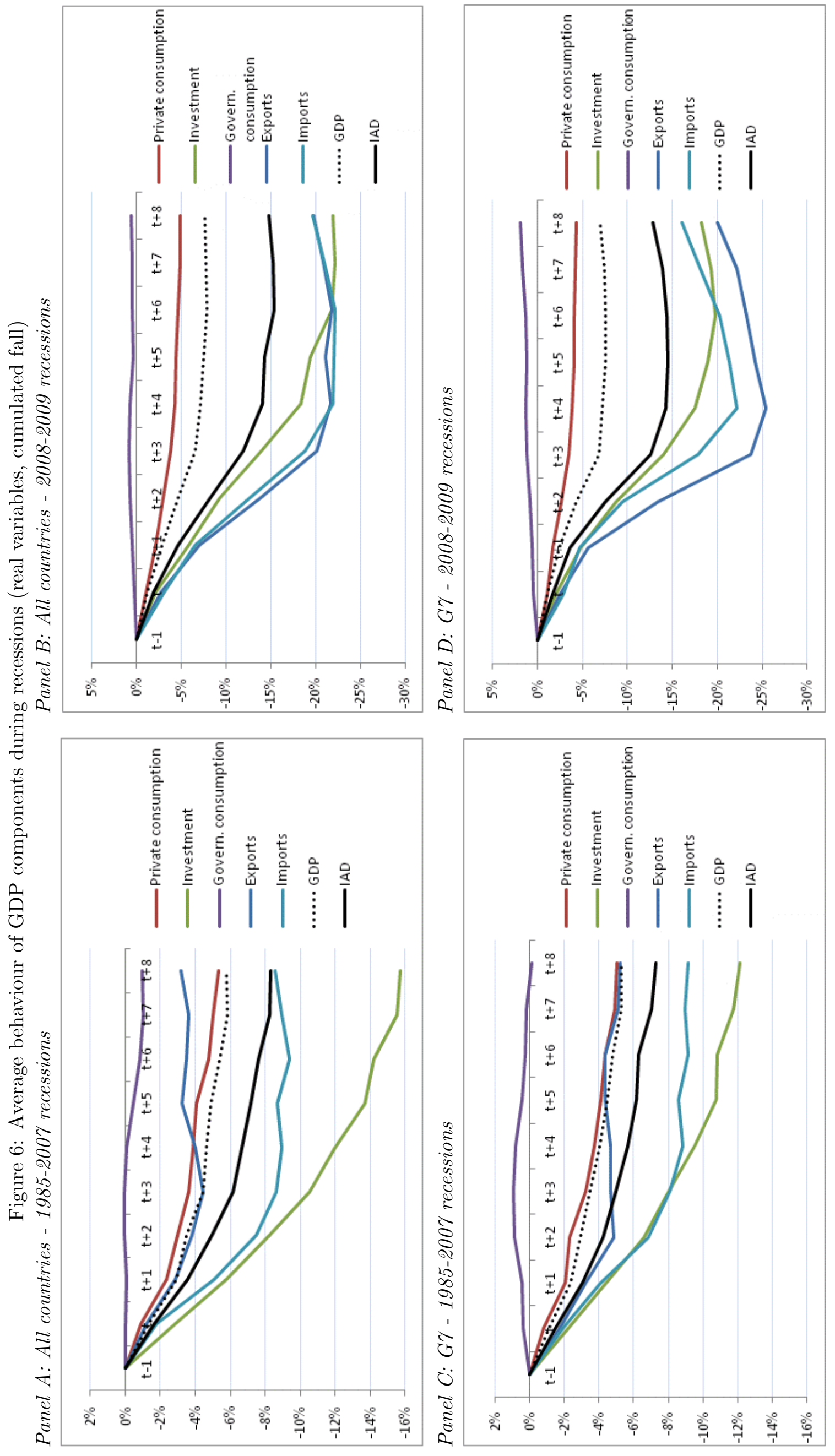

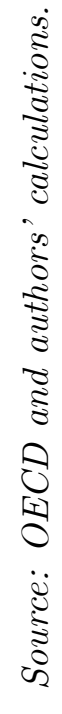


Figure 7: Actual vs. fitted values of real import growth - Selected economies

United States

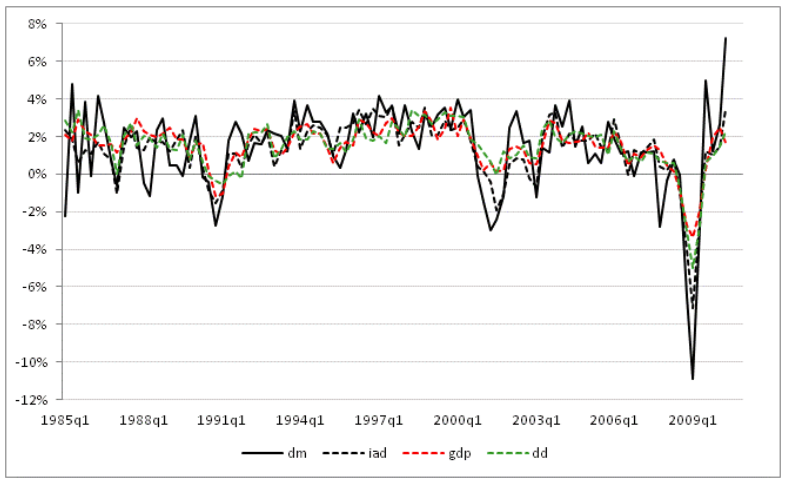

Germany
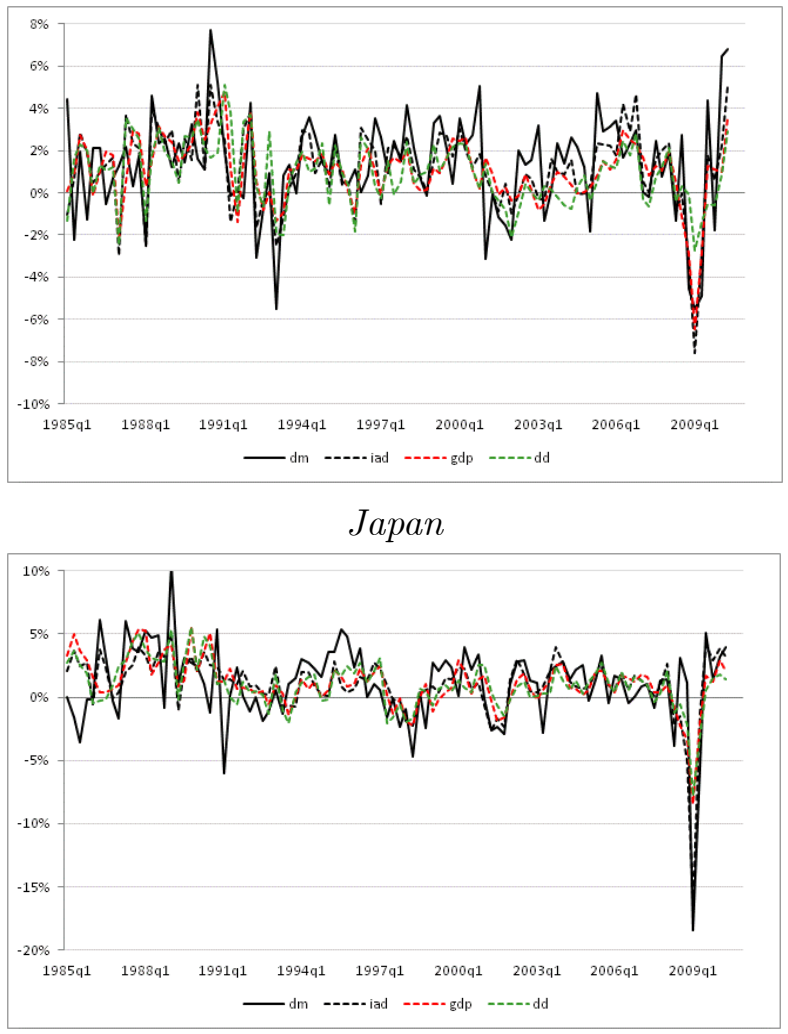

Italy

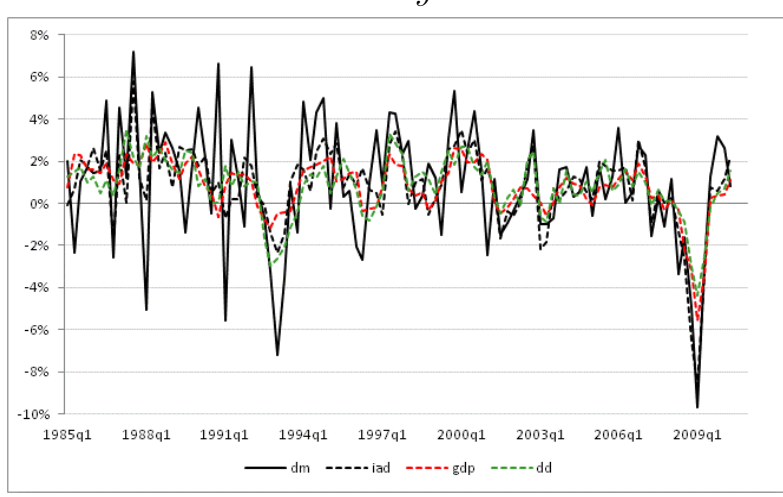

United Kingdom

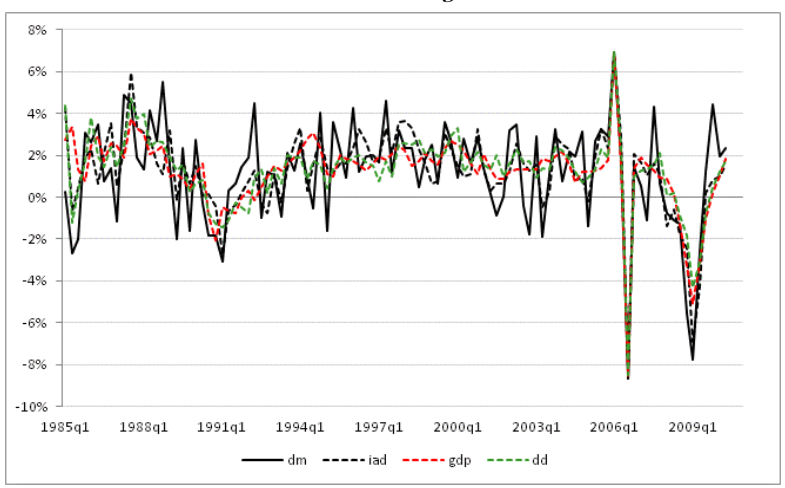

France

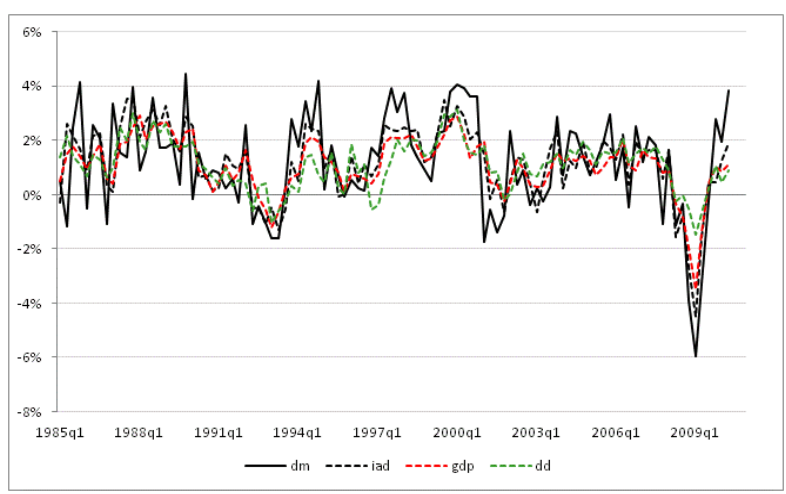

Canada

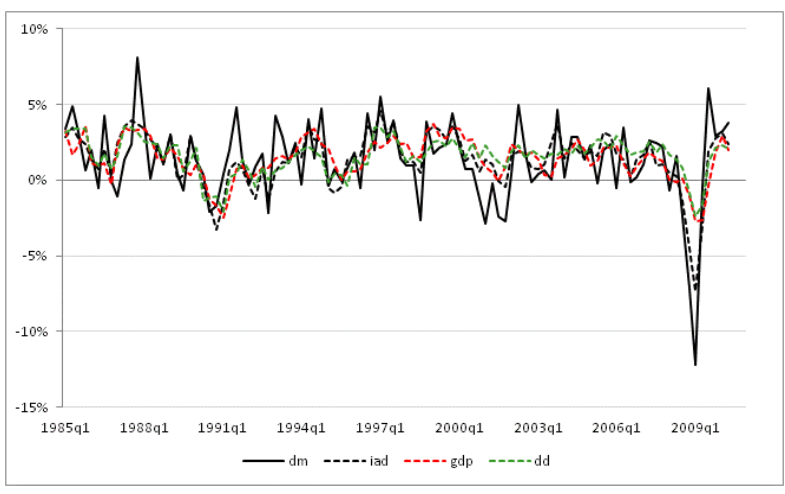

Spain

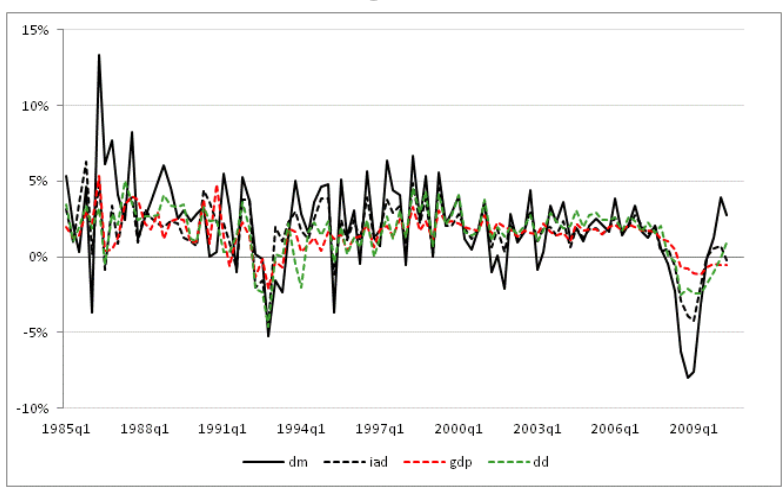

Notes: The solid line shows actual import growth, the dotted black line shows fitted values from the regression using $I A D$ as a measure of demand, the dotted red line from the GDP specification and the dotted green line from the domestic demand specification, $D D$. 

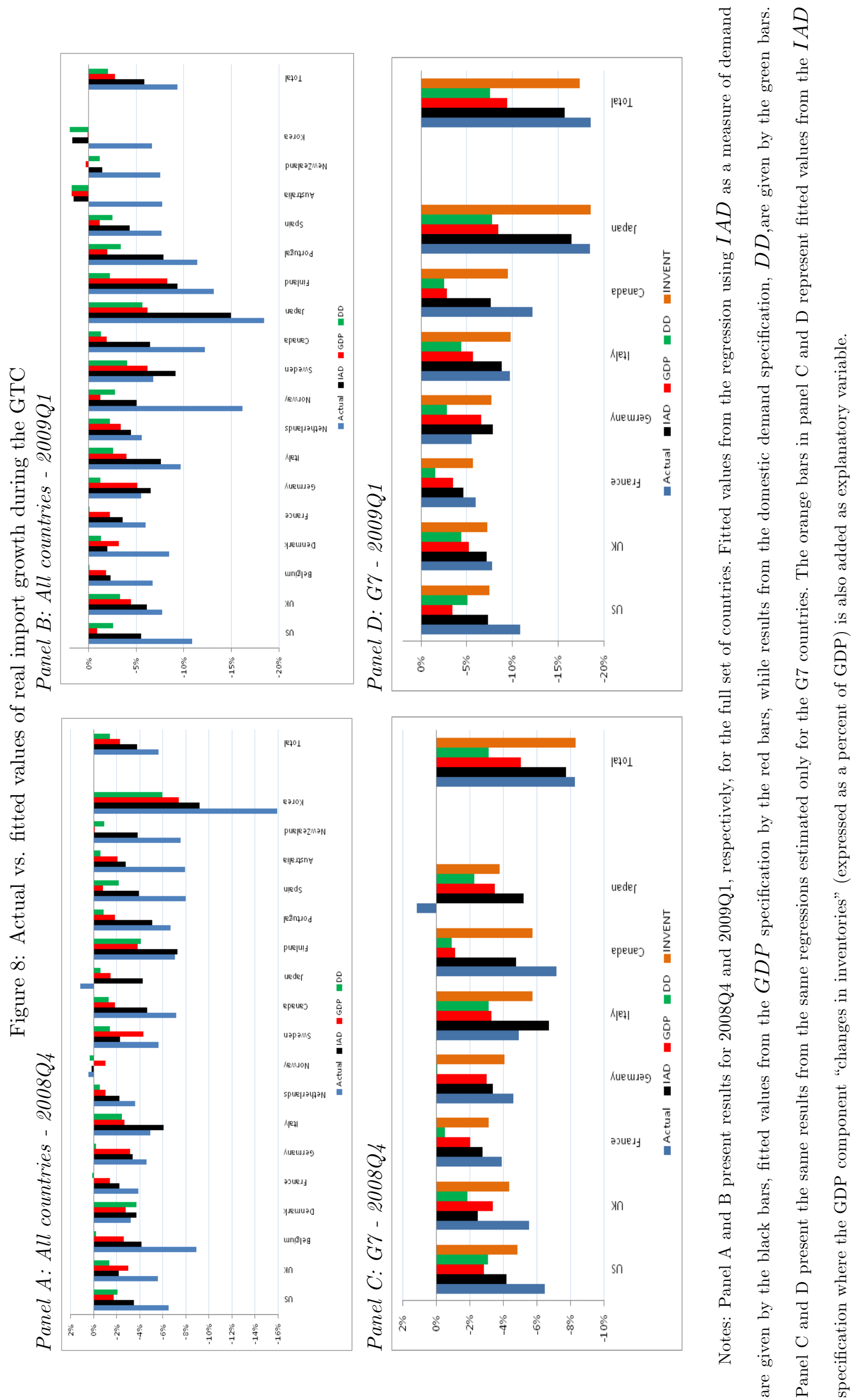
Table 1.a: Total import content of main GDP components

\begin{tabular}{|c|c|c|c|c|c|c|c|c|c|c|c|c|}
\hline \multirow[b]{3}{*}{ Australia } & \multicolumn{3}{|c|}{$\begin{array}{l}\text { Import content of private } \\
\text { consumption }\end{array}$} & \multicolumn{3}{|c|}{$\begin{array}{l}\text { Import content of government } \\
\text { consumption }\end{array}$} & \multicolumn{3}{|c|}{$\begin{array}{l}\text { Import content of total } \\
\text { investment }\end{array}$} & \multicolumn{3}{|c|}{ Import content of exports } \\
\hline & 1995 & 2000 & 2005 & 1995 & 2000 & 2005 & 1995 & 2000 & 2005 & 1995 & 2000 & 2005 \\
\hline & $17,0 \%$ & $18,6 \%$ & $18,4 \%$ & $9,0 \%$ & $10,0 \%$ & $9,9 \%$ & $26,5 \%$ & $26,6 \%$ & $26,0 \%$ & $14,0 \%$ & $14,1 \%$ & $14,0 \%$ \\
\hline Austria & $24,2 \%$ & $28,4 \%$ & $28,7 \%$ & $9,3 \%$ & $11,0 \%$ & $11,5 \%$ & $36,7 \%$ & $42,3 \%$ & $42,7 \%$ & $30,0 \%$ & $34,6 \%$ & $34,7 \%$ \\
\hline Belgium & $32,3 \%$ & $36,5 \%$ & $33,6 \%$ & $7,7 \%$ & $10,6 \%$ & $12,4 \%$ & $43,6 \%$ & $52,6 \%$ & $49,7 \%$ & $40,9 \%$ & $45,9 \%$ & $43,2 \%$ \\
\hline Canada & $25,9 \%$ & $23,7 \%$ & $25,8 \%$ & $10,3 \%$ & $10,0 \%$ & $9,8 \%$ & $39,0 \%$ & $42,1 \%$ & $34,8 \%$ & $30,5 \%$ & $30,9 \%$ & $27,4 \%$ \\
\hline Czech Republic & $34,0 \%$ & $39,5 \%$ & $38,6 \%$ & $18,8 \%$ & $20,3 \%$ & $19,8 \%$ & $39,2 \%$ & $53,3 \%$ & $52,1 \%$ & $29,1 \%$ & $45,6 \%$ & $48,3 \%$ \\
\hline Denmark & $21,4 \%$ & $30,3 \%$ & $31,8 \%$ & $7,1 \%$ & $8,9 \%$ & $10,4 \%$ & $34,3 \%$ & $40,3 \%$ & $39,1 \%$ & $27,1 \%$ & $32,3 \%$ & $34,9 \%$ \\
\hline Finland & $20,6 \%$ & $22,9 \%$ & $26,8 \%$ & $7,9 \%$ & $10,8 \%$ & $12,0 \%$ & $42,4 \%$ & $34,5 \%$ & $32,4 \%$ & $28,8 \%$ & $33,4 \%$ & $38,0 \%$ \\
\hline France & $19,4 \%$ & $22,0 \%$ & $22,7 \%$ & $8,2 \%$ & $8,0 \%$ & $8,7 \%$ & $24,7 \%$ & $27,2 \%$ & $25,4 \%$ & $19,8 \%$ & $26,5 \%$ & $27,0 \%$ \\
\hline Germany & $18,3 \%$ & $22,1 \%$ & $22,6 \%$ & $6,3 \%$ & $8,0 \%$ & $8,6 \%$ & $22,7 \%$ & $30,5 \%$ & $31,1 \%$ & $20,4 \%$ & $25,8 \%$ & $27,2 \%$ \\
\hline Greece & $21,0 \%$ & $24,4 \%$ & $24,1 \%$ & $11,6 \%$ & $19,4 \%$ & $9,9 \%$ & $35,0 \%$ & $36,5 \%$ & $35,5 \%$ & $15,8 \%$ & $26,9 \%$ & $25,9 \%$ \\
\hline Hungary & $47,1 \%$ & $35,4 \%$ & $35,6 \%$ & $29,2 \%$ & $16,5 \%$ & $15,4 \%$ & $60,0 \%$ & $53,6 \%$ & $49,1 \%$ & $47,4 \%$ & $58,6 \%$ & $55,8 \%$ \\
\hline Iceland & $30,7 \%$ & $16,9 \%$ & $14,8 \%$ & $17,4 \%$ & $6,2 \%$ & $5,5 \%$ & $41,7 \%$ & $24,1 \%$ & $24,4 \%$ & $26,7 \%$ & $26,9 \%$ & $27,1 \%$ \\
\hline Ireland & $46,3 \%$ & $42,0 \%$ & $37,2 \%$ & $16,4 \%$ & $13,8 \%$ & $14,4 \%$ & $51,5 \%$ & $48,6 \%$ & $41,5 \%$ & $48,7 \%$ & $53,3 \%$ & $50,7 \%$ \\
\hline Italy & $18,2 \%$ & $20,7 \%$ & $21,3 \%$ & $5,7 \%$ & $6,7 \%$ & $7,2 \%$ & $25,7 \%$ & $29,6 \%$ & $27,3 \%$ & $23,4 \%$ & $27,1 \%$ & $29,0 \%$ \\
\hline Japan & $9,1 \%$ & $9,8 \%$ & $11,7 \%$ & $3,0 \%$ & $2,8 \%$ & $6,0 \%$ & $8,2 \%$ & $10,6 \%$ & $15,3 \%$ & $8,4 \%$ & $9,6 \%$ & $15,4 \%$ \\
\hline Korea & $21,4 \%$ & $23,8 \%$ & $24,2 \%$ & $11,4 \%$ & $10,2 \%$ & $10,5 \%$ & $30,8 \%$ & $35,5 \%$ & $28,9 \%$ & $29,9 \%$ & $38,1 \%$ & $38,6 \%$ \\
\hline Luxembourg & $45,5 \%$ & $51,8 \%$ & $50,3 \%$ & $15,7 \%$ & $18,1 \%$ & $18,4 \%$ & $49,9 \%$ & $54,7 \%$ & $53,6 \%$ & $41,3 \%$ & $57,7 \%$ & $60,4 \%$ \\
\hline Mexico & $31,4 \%$ & $18,6 \%$ & $17,2 \%$ & $8,3 \%$ & $5,0 \%$ & $4,7 \%$ & $42,6 \%$ & $32,0 \%$ & $30,2 \%$ & $42,5 \%$ & $39,3 \%$ & $33,2 \%$ \\
\hline Netherlands & $26,2 \%$ & $28,5 \%$ & $30,3 \%$ & $10,4 \%$ & $11,2 \%$ & $11,3 \%$ & $41,6 \%$ & $41,6 \%$ & $39,3 \%$ & $33,3 \%$ & $36,9 \%$ & $34,9 \%$ \\
\hline New Zealand & $21,1 \%$ & $23,8 \%$ & $21,4 \%$ & $10,1 \%$ & $11,6 \%$ & $9,8 \%$ & $37,9 \%$ & $41,2 \%$ & $39,3 \%$ & $18,1 \%$ & $19,2 \%$ & $17,5 \%$ \\
\hline Norway & $29,1 \%$ & $31,8 \%$ & $32,0 \%$ & $11,1 \%$ & $10,9 \%$ & $10,9 \%$ & $42,1 \%$ & $42,0 \%$ & $36,4 \%$ & $21,6 \%$ & $16,9 \%$ & $16,2 \%$ \\
\hline Poland & $19,7 \%$ & $26,3 \%$ & $24,9 \%$ & $8,0 \%$ & $6,4 \%$ & $9,5 \%$ & $30,0 \%$ & $45,8 \%$ & $47,9 \%$ & $16,8 \%$ & $24,7 \%$ & $30,6 \%$ \\
\hline Portugal & $27,5 \%$ & $32,5 \%$ & $29,0 \%$ & $8,7 \%$ & $10,9 \%$ & $9,5 \%$ & $35,3 \%$ & $38,3 \%$ & $36,1 \%$ & $35,8 \%$ & $30,8 \%$ & $38,9 \%$ \\
\hline Slovak Republic & $38,2 \%$ & $43,1 \%$ & $44,7 \%$ & $17,7 \%$ & $16,3 \%$ & $21,6 \%$ & $53,6 \%$ & $52,2 \%$ & $57,3 \%$ & $35,4 \%$ & $50,3 \%$ & $48,6 \%$ \\
\hline Spain & $18,1 \%$ & $23,1 \%$ & $24,0 \%$ & $7,3 \%$ & $9,9 \%$ & $11,3 \%$ & $26,1 \%$ & $34,6 \%$ & $28,3 \%$ & $26,6 \%$ & $33,9 \%$ & $34,2 \%$ \\
\hline Sweden & $23,2 \%$ & $26,4 \%$ & $28,1 \%$ & $10,5 \%$ & $11,3 \%$ & $11,2 \%$ & $43,7 \%$ & $47,8 \%$ & $43,0 \%$ & $28,9 \%$ & $32,3 \%$ & $33,2 \%$ \\
\hline Switzerland & $16,3 \%$ & $22,5 \%$ & $24,4 \%$ & $5,8 \%$ & $9,2 \%$ & $9,3 \%$ & $26,6 \%$ & $33,1 \%$ & $33,9 \%$ & $14,2 \%$ & $23,1 \%$ & $25,3 \%$ \\
\hline Turkey & $18,1 \%$ & $15,8 \%$ & $23,0 \%$ & $6,0 \%$ & $10,3 \%$ & $14,6 \%$ & $36,8 \%$ & $33,7 \%$ & $41,7 \%$ & $13,9 \%$ & $13,6 \%$ & $30,7 \%$ \\
\hline United Kingdom & $21,1 \%$ & $24,9 \%$ & $27,2 \%$ & $11,2 \%$ & $12,7 \%$ & $12,5 \%$ & $37,4 \%$ & $35,0 \%$ & $25,4 \%$ & $22,2 \%$ & $20,3 \%$ & $18,6 \%$ \\
\hline United States & $8,7 \%$ & $10,5 \%$ & $11,9 \%$ & $3,7 \%$ & $6,0 \%$ & $6,2 \%$ & $18,4 \%$ & $19,1 \%$ & $17,3 \%$ & $9,5 \%$ & $11,0 \%$ & $12,3 \%$ \\
\hline Argentina & $8,2 \%$ & $7,9 \%$ & $12,4 \%$ & $2,2 \%$ & $1,8 \%$ & $2,8 \%$ & $22,6 \%$ & $22,6 \%$ & $27,1 \%$ & $10,3 \%$ & $10,9 \%$ & $16,8 \%$ \\
\hline Brazil & $9,6 \%$ & $12,2 \%$ & $10,4 \%$ & $3,3 \%$ & $4,8 \%$ & $3,7 \%$ & $13,1 \%$ & $14,6 \%$ & $20,9 \%$ & $10,8 \%$ & $12,0 \%$ & $14,4 \%$ \\
\hline China & $11,4 \%$ & $13,4 \%$ & $19,1 \%$ & $9,9 \%$ & $10,8 \%$ & $13,8 \%$ & $26,2 \%$ & $20,8 \%$ & $28,8 \%$ & $15,5 \%$ & $19,6 \%$ & $27,4 \%$ \\
\hline Chinese Taipei & $24,4 \%$ & $22,9 \%$ & $26,3 \%$ & $13,6 \%$ & $9,3 \%$ & $8,7 \%$ & $42,0 \%$ & $49,9 \%$ & $50,6 \%$ & $35,2 \%$ & $37,3 \%$ & $48,3 \%$ \\
\hline India & $7,6 \%$ & $10,4 \%$ & $14,0 \%$ & $5,9 \%$ & $8,1 \%$ & $8,3 \%$ & $21,6 \%$ & $23,7 \%$ & $28,7 \%$ & $10,4 \%$ & $12,4 \%$ & $18,5 \%$ \\
\hline Indonesia & $16,9 \%$ & $23,3 \%$ & $22,4 \%$ & $12,4 \%$ & $14,0 \%$ & $13,9 \%$ & $30,6 \%$ & $35,5 \%$ & $30,4 \%$ & $15,1 \%$ & $19,5 \%$ & $18,1 \%$ \\
\hline Israel & $20,1 \%$ & $30,2 \%$ & $29,6 \%$ & $6,2 \%$ & $14,9 \%$ & $15,5 \%$ & $21,4 \%$ & $38,3 \%$ & $39,5 \%$ & $16,6 \%$ & $34,1 \%$ & $37,9 \%$ \\
\hline Russian Fed. & $22,8 \%$ & $24,7 \%$ & $23,2 \%$ & $10,6 \%$ & $12,1 \%$ & $12,2 \%$ & $20,0 \%$ & $25,7 \%$ & $26,0 \%$ & $10,6 \%$ & $10,9 \%$ & $9,1 \%$ \\
\hline Singapore & $45,9 \%$ & $43,0 \%$ & $46,7 \%$ & $27,6 \%$ & $35,0 \%$ & $35,4 \%$ & $58,2 \%$ & $59,0 \%$ & $64,0 \%$ & $57,2 \%$ & $58,4 \%$ & $56,6 \%$ \\
\hline South Africa & $14,3 \%$ & $18,4 \%$ & $20,6 \%$ & $5,5 \%$ & $7,1 \%$ & $8,7 \%$ & $29,5 \%$ & $37,4 \%$ & $34,5 \%$ & $9,7 \%$ & $15,2 \%$ & $14,6 \%$ \\
\hline Hong Kong & $12,0 \%$ & $9,5 \%$ & $7,0 \%$ & $8,4 \%$ & $9,7 \%$ & $6,3 \%$ & $14,0 \%$ & $10,2 \%$ & $5,9 \%$ & $13,9 \%$ & $14,1 \%$ & $12,6 \%$ \\
\hline Chile & $23,4 \%$ & $27,8 \%$ & $31,7 \%$ & $8,5 \%$ & $8,2 \%$ & $9,8 \%$ & $39,4 \%$ & $35,2 \%$ & $37,6 \%$ & $19,0 \%$ & $19,0 \%$ & $23,2 \%$ \\
\hline Estonia & $49,8 \%$ & $40,0 \%$ & $41,3 \%$ & $25,1 \%$ & $19,1 \%$ & $18,5 \%$ & $69,2 \%$ & $58,8 \%$ & $55,5 \%$ & $47,5 \%$ & $55,1 \%$ & $50,8 \%$ \\
\hline Slovenia & $39,0 \%$ & $36,2 \%$ & $37,6 \%$ & $19,6 \%$ & $16,3 \%$ & $15,7 \%$ & $54,2 \%$ & $54,7 \%$ & $50,6 \%$ & $36,9 \%$ & $43,6 \%$ & $45,6 \%$ \\
\hline Malaysia & $46,7 \%$ & $41,8 \%$ & $42,3 \%$ & $24,4 \%$ & $24,4 \%$ & $25,2 \%$ & $55,9 \%$ & $64,1 \%$ & $62,3 \%$ & $38,8 \%$ & $53,0 \%$ & $50,4 \%$ \\
\hline Philippines & $25,1 \%$ & $28,5 \%$ & $32,1 \%$ & $12,0 \%$ & $11,8 \%$ & $8,3 \%$ & $41,2 \%$ & $52,3 \%$ & $53,1 \%$ & $32,4 \%$ & $46,0 \%$ & $41,6 \%$ \\
\hline Thailand & $28,9 \%$ & $31,7 \%$ & $26,9 \%$ & $8,2 \%$ & $9,7 \%$ & $10,5 \%$ & $42,3 \%$ & $52,5 \%$ & $61,8 \%$ & $33,5 \%$ & $40,6 \%$ & $38,1 \%$ \\
\hline Romania & $22,4 \%$ & $24,1 \%$ & $26,9 \%$ & $19,0 \%$ & $20,8 \%$ & $17,8 \%$ & $35,8 \%$ & $47,9 \%$ & $51,7 \%$ & $26,0 \%$ & $27,9 \%$ & $29,0 \%$ \\
\hline Vietnam & $16,3 \%$ & $33,3 \%$ & $36,9 \%$ & $12,2 \%$ & $26,3 \%$ & $28,8 \%$ & $40,5 \%$ & $50,6 \%$ & $54,3 \%$ & $15,0 \%$ & $27,5 \%$ & $30,6 \%$ \\
\hline Saudi Arabia & $17,4 \%$ & $30,5 \%$ & $34,8 \%$ & $12,7 \%$ & $18,8 \%$ & $14,2 \%$ & $19,6 \%$ & $48,4 \%$ & $52,6 \%$ & $1,3 \%$ & $5,9 \%$ & \\
\hline
\end{tabular}

Source: OECD Input-Output Tables and authors' calculations. 
Table 1.b: Induced import content of main GDP components

\begin{tabular}{|c|c|c|c|c|c|c|c|c|c|}
\hline \multirow[b]{3}{*}{ Australia } & \multicolumn{3}{|c|}{$\begin{array}{l}\text { Import content of private } \\
\text { consumption }\end{array}$} & \multicolumn{3}{|c|}{$\begin{array}{l}\text { Import content of government } \\
\text { consumption }\end{array}$} & \multicolumn{3}{|c|}{$\begin{array}{l}\text { Import content of total } \\
\text { investment }\end{array}$} \\
\hline & 1995 & 2000 & 2005 & 1995 & 2000 & 2005 & 1995 & 2000 & 2005 \\
\hline & $9,1 \%$ & $9,1 \%$ & $8,8 \%$ & $9,0 \%$ & $8,9 \%$ & $8,7 \%$ & $11,1 \%$ & $11,1 \%$ & $11,1 \%$ \\
\hline Austria & $11,0 \%$ & $13,3 \%$ & $13,8 \%$ & $7,8 \%$ & $9,1 \%$ & $9,2 \%$ & $16,2 \%$ & $16,0 \%$ & $18,1 \%$ \\
\hline Belgium & $17,4 \%$ & $19,5 \%$ & $18,9 \%$ & $7,3 \%$ & $9,5 \%$ & $11,2 \%$ & $21,6 \%$ & $23,8 \%$ & $21,0 \%$ \\
\hline Canada & $11,3 \%$ & $10,6 \%$ & $9,4 \%$ & $10,3 \%$ & $10,0 \%$ & $9,8 \%$ & $16,1 \%$ & $15,3 \%$ & $15,6 \%$ \\
\hline Czech Republic & $19,1 \%$ & $20,6 \%$ & $20,5 \%$ & $14,2 \%$ & $17,6 \%$ & $14,4 \%$ & $21,0 \%$ & $23,9 \%$ & $20,9 \%$ \\
\hline Denmark & $9,9 \%$ & $11,7 \%$ & $13,3 \%$ & $6,4 \%$ & $8,1 \%$ & $9,3 \%$ & $15,3 \%$ & $17,5 \%$ & $19,0 \%$ \\
\hline Finland & $10,7 \%$ & $12,7 \%$ & $13,3 \%$ & $7,1 \%$ & $9,8 \%$ & $10,8 \%$ & $12,3 \%$ & $18,4 \%$ & $18,4 \%$ \\
\hline France & $9,3 \%$ & $11,0 \%$ & $10,7 \%$ & $6,5 \%$ & $6,8 \%$ & $6,8 \%$ & $12,1 \%$ & $13,5 \%$ & $13,0 \%$ \\
\hline Germany & $9,0 \%$ & $11,7 \%$ & $12,0 \%$ & $5,5 \%$ & $7,0 \%$ & $7,1 \%$ & $11,7 \%$ & $14,5 \%$ & $15,4 \%$ \\
\hline Greece & $8,8 \%$ & $11,3 \%$ & $10,0 \%$ & $10,6 \%$ & $18,1 \%$ & $10,2 \%$ & $17,0 \%$ & $14,0 \%$ & $13,8 \%$ \\
\hline Hungary & $25,6 \%$ & $23,7 \%$ & $18,5 \%$ & $19,5 \%$ & $13,5 \%$ & $11,4 \%$ & $22,3 \%$ & $20,8 \%$ & $20,7 \%$ \\
\hline Iceland & $14,8 \%$ & $9,2 \%$ & $8,0 \%$ & $13,7 \%$ & $6,2 \%$ & $5,5 \%$ & $13,2 \%$ & $5,4 \%$ & $5,7 \%$ \\
\hline Ireland & $16,3 \%$ & $16,1 \%$ & $19,6 \%$ & $13,1 \%$ & $13,8 \%$ & $14,4 \%$ & $23,0 \%$ & $21,7 \%$ & $22,8 \%$ \\
\hline Italy & $11,8 \%$ & $13,2 \%$ & $13,1 \%$ & $5,4 \%$ & $6,2 \%$ & $6,6 \%$ & $14,7 \%$ & $15,6 \%$ & $14,8 \%$ \\
\hline Japan & $4,6 \%$ & $5,1 \%$ & $6,9 \%$ & $3,0 \%$ & $2,8 \%$ & $6,0 \%$ & $5,6 \%$ & $6,4 \%$ & $9,1 \%$ \\
\hline Korea & $14,8 \%$ & $16,6 \%$ & $16,0 \%$ & $11,4 \%$ & $10,2 \%$ & $10,5 \%$ & $15,4 \%$ & $17,8 \%$ & $17,8 \%$ \\
\hline Luxembourg & $15,4 \%$ & $18,8 \%$ & $22,1 \%$ & $13,0 \%$ & $15,8 \%$ & $16,7 \%$ & $19,3 \%$ & $22,1 \%$ & $30,8 \%$ \\
\hline Mexico & $18,0 \%$ & $11,7 \%$ & $11,2 \%$ & $8,3 \%$ & $5,0 \%$ & $4,6 \%$ & $26,8 \%$ & $16,2 \%$ & $14,4 \%$ \\
\hline Netherlands & $13,8 \%$ & $14,5 \%$ & $15,8 \%$ & $9,2 \%$ & $10,0 \%$ & $10,3 \%$ & $19,7 \%$ & $19,0 \%$ & $16,3 \%$ \\
\hline New Zealand & $11,5 \%$ & $12,6 \%$ & $11,0 \%$ & $8,8 \%$ & $10,4 \%$ & $8,9 \%$ & $14,4 \%$ & $15,3 \%$ & $13,5 \%$ \\
\hline Norway & $13,2 \%$ & $12,8 \%$ & $11,9 \%$ & $10,0 \%$ & $9,5 \%$ & $9,3 \%$ & $15,0 \%$ & $14,2 \%$ & $14,1 \%$ \\
\hline Poland & $12,2 \%$ & $14,3 \%$ & $14,8 \%$ & $6,9 \%$ & $6,0 \%$ & $7,8 \%$ & $15,0 \%$ & $14,3 \%$ & $15,9 \%$ \\
\hline Portugal & $14,6 \%$ & $15,2 \%$ & $14,7 \%$ & $7,7 \%$ & $8,3 \%$ & $7,9 \%$ & $16,0 \%$ & $16,4 \%$ & $17,0 \%$ \\
\hline Slovak Republic & $18,8 \%$ & $20,7 \%$ & $17,5 \%$ & $17,7 \%$ & $16,3 \%$ & $12,7 \%$ & $18,7 \%$ & $21,9 \%$ & $18,2 \%$ \\
\hline Spain & $10,7 \%$ & $12,8 \%$ & $12,2 \%$ & $6,7 \%$ & $8,8 \%$ & $9,0 \%$ & $12,7 \%$ & $15,6 \%$ & $14,0 \%$ \\
\hline Sweden & $12,6 \%$ & $14,1 \%$ & $14,7 \%$ & $9,5 \%$ & $10,0 \%$ & $9,6 \%$ & $15,7 \%$ & $15,9 \%$ & $17,2 \%$ \\
\hline Switzerland & $8,3 \%$ & $11,0 \%$ & $13,2 \%$ & $5,8 \%$ & $9,1 \%$ & $9,2 \%$ & $11,0 \%$ & $17,5 \%$ & $18,3 \%$ \\
\hline Turkey & $9,6 \%$ & $11,6 \%$ & $14,5 \%$ & $6,0 \%$ & $6,8 \%$ & $10,7 \%$ & $11,0 \%$ & $13,0 \%$ & $21,0 \%$ \\
\hline United Kingdom & $11,7 \%$ & $10,4 \%$ & $10,5 \%$ & $11,2 \%$ & $12,3 \%$ & $12,5 \%$ & $12,2 \%$ & $11,7 \%$ & $11,4 \%$ \\
\hline United States & $4,1 \%$ & $4,6 \%$ & $5,8 \%$ & $3,7 \%$ & $4,5 \%$ & $6,2 \%$ & $7,8 \%$ & $7,8 \%$ & $9,0 \%$ \\
\hline Argentina & $4,9 \%$ & $4,5 \%$ & $6,3 \%$ & $2,2 \%$ & $1,8 \%$ & $2,8 \%$ & $7,1 \%$ & $7,1 \%$ & $11,6 \%$ \\
\hline Brazil & $5,7 \%$ & $7,2 \%$ & $7,1 \%$ & $3,3 \%$ & $4,8 \%$ & $3,7 \%$ & $5,9 \%$ & $7,7 \%$ & $11,0 \%$ \\
\hline China & $9,6 \%$ & $10,3 \%$ & $14,0 \%$ & $9,5 \%$ & $10,6 \%$ & $13,6 \%$ & $11,5 \%$ & $15,4 \%$ & $20,5 \%$ \\
\hline Chinese Taipei & $12,9 \%$ & $11,9 \%$ & $15,4 \%$ & $13,6 \%$ & $9,3 \%$ & $8,7 \%$ & $18,9 \%$ & $18,4 \%$ & $21,0 \%$ \\
\hline India & $5,5 \%$ & $6,4 \%$ & $11,4 \%$ & $4,2 \%$ & $4,4 \%$ & $8,3 \%$ & $12,1 \%$ & $13,3 \%$ & $19,9 \%$ \\
\hline Indonesia & $9,7 \%$ & $11,2 \%$ & $12,2 \%$ & $9,8 \%$ & $12,0 \%$ & $12,1 \%$ & $18,1 \%$ & $21,8 \%$ & $19,8 \%$ \\
\hline Israel & $9,1 \%$ & $14,8 \%$ & $15,0 \%$ & $6,2 \%$ & $14,9 \%$ & $15,5 \%$ & $11,3 \%$ & $19,3 \%$ & $20,6 \%$ \\
\hline Russian Fed. & $8,9 \%$ & $9,5 \%$ & $9,3 \%$ & $9,9 \%$ & $11,7 \%$ & $11,7 \%$ & $10,8 \%$ & $13,2 \%$ & $13,5 \%$ \\
\hline Singapore & $17,4 \%$ & $18,7 \%$ & $20,3 \%$ & $27,6 \%$ & $35,0 \%$ & $35,4 \%$ & $20,5 \%$ & $23,3 \%$ & $25,4 \%$ \\
\hline South Africa & $7,6 \%$ & $10,4 \%$ & $11,0 \%$ & $5,5 \%$ & $7,1 \%$ & $8,7 \%$ & $10,0 \%$ & $13,4 \%$ & $16,1 \%$ \\
\hline Hong Kong & $7,0 \%$ & $5,7 \%$ & $4,5 \%$ & $8,4 \%$ & $9,7 \%$ & $6,3 \%$ & $7,3 \%$ & $4,9 \%$ & $2,3 \%$ \\
\hline Chile & $12,9 \%$ & $15,7 \%$ & $17,3 \%$ & $8,5 \%$ & $8,2 \%$ & $9,8 \%$ & $12,0 \%$ & $12,3 \%$ & $14,7 \%$ \\
\hline Estonia & $23,3 \%$ & $19,6 \%$ & $18,7 \%$ & $16,7 \%$ & $17,3 \%$ & $16,2 \%$ & $19,1 \%$ & $21,5 \%$ & $20,6 \%$ \\
\hline Slovenia & $14,7 \%$ & $14,3 \%$ & $13,9 \%$ & $16,1 \%$ & $12,4 \%$ & $11,6 \%$ & $18,7 \%$ & $18,3 \%$ & $19,7 \%$ \\
\hline Malaysia & $20,8 \%$ & $21,9 \%$ & $23,3 \%$ & $13,1 \%$ & $22,2 \%$ & $22,4 \%$ & $20,0 \%$ & $21,8 \%$ & $19,9 \%$ \\
\hline Philippines & $14,6 \%$ & $15,2 \%$ & $15,6 \%$ & $12,0 \%$ & $11,8 \%$ & $8,3 \%$ & $17,1 \%$ & $16,9 \%$ & $17,6 \%$ \\
\hline Thailand & $15,3 \%$ & $17,3 \%$ & $21,8 \%$ & $5,8 \%$ & $9,7 \%$ & $10,1 \%$ & $19,9 \%$ & $20,1 \%$ & $25,3 \%$ \\
\hline Romania & $12,2 \%$ & $15,7 \%$ & $17,2 \%$ & $18,0 \%$ & $20,8 \%$ & $17,8 \%$ & $18,4 \%$ & $15,4 \%$ & $14,0 \%$ \\
\hline Vietnam & $12,3 \%$ & $21,5 \%$ & $23,9 \%$ & $12,2 \%$ & $26,3 \%$ & $28,8 \%$ & $27,6 \%$ & $37,6 \%$ & $41,4 \%$ \\
\hline Saudi Arabia & $3,7 \%$ & $7,0 \%$ & $8,3 \%$ & $7,3 \%$ & $11,9 \%$ & $6,7 \%$ & $2,4 \%$ & $9,9 \%$ & $11,9 \%$ \\
\hline
\end{tabular}

Source: OECD Input-Output Tables and authors' calculations. 
Table 1.c: Direct import content of main GDP components

\begin{tabular}{|c|c|c|c|c|c|c|c|c|c|}
\hline \multirow[b]{3}{*}{ Australia } & \multicolumn{3}{|c|}{$\begin{array}{l}\text { Import content of private } \\
\text { consumption }\end{array}$} & \multicolumn{3}{|c|}{$\begin{array}{l}\text { Import content of government } \\
\text { consumption }\end{array}$} & \multicolumn{3}{|c|}{$\begin{array}{l}\text { Import content of total } \\
\text { investment }\end{array}$} \\
\hline & 1995 & 2000 & 2005 & 1995 & 2000 & 2005 & 1995 & 2000 & 2005 \\
\hline & $7,9 \%$ & $9,5 \%$ & $9,6 \%$ & $0,0 \%$ & $1,0 \%$ & $1,2 \%$ & $15,4 \%$ & $15,5 \%$ & $15 \%$ \\
\hline Austria & $13,2 \%$ & $15,1 \%$ & $14,9 \%$ & $1,4 \%$ & $1,9 \%$ & $2,2 \%$ & $20,5 \%$ & $26,3 \%$ & $25 \%$ \\
\hline Belgium & $14,8 \%$ & $17,0 \%$ & $14,8 \%$ & $0,5 \%$ & $1,1 \%$ & $1,2 \%$ & $22,0 \%$ & $28,7 \%$ & $29 \%$ \\
\hline Canada & $14,6 \%$ & $13,2 \%$ & $16,4 \%$ & $0,0 \%$ & $0,0 \%$ & $0,0 \%$ & $22,9 \%$ & $26,8 \%$ & $19 \%$ \\
\hline Czech Republic & $15,0 \%$ & $19,0 \%$ & $18,1 \%$ & $4,6 \%$ & $2,6 \%$ & $5,4 \%$ & $18,1 \%$ & $29,4 \%$ & $31 \%$ \\
\hline Denmark & $11,5 \%$ & $18,6 \%$ & $18,5 \%$ & $0,7 \%$ & $0,9 \%$ & $1,1 \%$ & $18,9 \%$ & $22,9 \%$ & $20 \%$ \\
\hline Finland & $9,9 \%$ & $10,1 \%$ & $13,6 \%$ & $0,8 \%$ & $1,0 \%$ & $1,2 \%$ & $30,1 \%$ & $16,1 \%$ & $14 \%$ \\
\hline France & $10,1 \%$ & $11,0 \%$ & $12,0 \%$ & $1,7 \%$ & $1,2 \%$ & $1,9 \%$ & $12,6 \%$ & $13,7 \%$ & $12 \%$ \\
\hline Germany & $9,3 \%$ & $10,3 \%$ & $10,5 \%$ & $0,8 \%$ & $1,0 \%$ & $1,5 \%$ & $11,0 \%$ & $16,1 \%$ & $16 \%$ \\
\hline Greece & $12,2 \%$ & $13,1 \%$ & $14,1 \%$ & $1,0 \%$ & $1,3 \%$ & $-0,3 \%$ & $18,0 \%$ & $22,4 \%$ & $22 \%$ \\
\hline Hungary & $21,5 \%$ & $11,7 \%$ & $17,0 \%$ & $9,7 \%$ & $3,0 \%$ & $4,1 \%$ & $37,7 \%$ & $32,8 \%$ & $28 \%$ \\
\hline Iceland & $15,9 \%$ & $7,7 \%$ & $6,8 \%$ & $3,7 \%$ & $0,0 \%$ & $0,0 \%$ & $28,5 \%$ & $18,7 \%$ & $19 \%$ \\
\hline Ireland & $30,0 \%$ & $25,9 \%$ & $17,6 \%$ & $3,3 \%$ & $0,0 \%$ & $0,0 \%$ & $28,5 \%$ & $26,9 \%$ & $19 \%$ \\
\hline Italy & $6,4 \%$ & $7,5 \%$ & $8,1 \%$ & $0,3 \%$ & $0,5 \%$ & $0,6 \%$ & $11,0 \%$ & $14,0 \%$ & $13 \%$ \\
\hline Japan & $4,5 \%$ & $4,7 \%$ & $4,8 \%$ & $0,0 \%$ & $0,0 \%$ & $0,0 \%$ & $2,6 \%$ & $4,3 \%$ & $6 \%$ \\
\hline Korea & $6,6 \%$ & $7,2 \%$ & $8,2 \%$ & $0,0 \%$ & $0,0 \%$ & $0,0 \%$ & $15,4 \%$ & $17,7 \%$ & $11 \%$ \\
\hline Luxembourg & $30,1 \%$ & $33,0 \%$ & $28,1 \%$ & $2,6 \%$ & $2,2 \%$ & $1,7 \%$ & $30,6 \%$ & $32,7 \%$ & $23 \%$ \\
\hline Mexico & $13,4 \%$ & $6,9 \%$ & $6,0 \%$ & $0,1 \%$ & $0,1 \%$ & $0,0 \%$ & $15,8 \%$ & $15,8 \%$ & $16 \%$ \\
\hline Netherlands & $12,3 \%$ & $14,1 \%$ & $14,6 \%$ & $1,2 \%$ & $1,2 \%$ & $0,9 \%$ & $21,9 \%$ & $22,7 \%$ & $23 \%$ \\
\hline New Zealand & $9,6 \%$ & $11,2 \%$ & $10,4 \%$ & $1,3 \%$ & $1,2 \%$ & $0,9 \%$ & $23,6 \%$ & $25,9 \%$ & $26 \%$ \\
\hline Norway & $15,8 \%$ & $19,1 \%$ & $20,1 \%$ & $1,1 \%$ & $1,5 \%$ & $1,6 \%$ & $27,1 \%$ & $27,8 \%$ & $22 \%$ \\
\hline Poland & $7,5 \%$ & $12,0 \%$ & $10,1 \%$ & $1,0 \%$ & $0,4 \%$ & $1,7 \%$ & $15,0 \%$ & $31,5 \%$ & $32 \%$ \\
\hline Portugal & $13,0 \%$ & $17,3 \%$ & $14,4 \%$ & $0,9 \%$ & $2,6 \%$ & $1,6 \%$ & $19,3 \%$ & $21,9 \%$ & $19 \%$ \\
\hline Slovak Republic & $19,4 \%$ & $22,4 \%$ & $27,2 \%$ & $0,0 \%$ & $0,0 \%$ & $8,9 \%$ & $34,9 \%$ & $30,3 \%$ & $39 \%$ \\
\hline Spain & $7,4 \%$ & $10,3 \%$ & $11,8 \%$ & $0,6 \%$ & $1,1 \%$ & $2,4 \%$ & $13,5 \%$ & $19,0 \%$ & $14 \%$ \\
\hline Sweden & $10,6 \%$ & $12,4 \%$ & $13,5 \%$ & $1,0 \%$ & $1,3 \%$ & $1,6 \%$ & $28,0 \%$ & $31,9 \%$ & $26 \%$ \\
\hline Switzerland & $8,0 \%$ & $11,5 \%$ & $11,2 \%$ & $0,1 \%$ & $0,1 \%$ & $0,1 \%$ & $15,6 \%$ & $15,6 \%$ & $16 \%$ \\
\hline Turkey & $8,5 \%$ & $4,2 \%$ & $8,4 \%$ & $0,0 \%$ & $3,4 \%$ & $3,9 \%$ & $25,8 \%$ & $20,7 \%$ & $21 \%$ \\
\hline United Kingdom & $9,4 \%$ & $14,5 \%$ & $16,7 \%$ & $0,0 \%$ & $0,4 \%$ & $0,0 \%$ & $25,2 \%$ & $23,4 \%$ & $14 \%$ \\
\hline United States & $4,5 \%$ & $6,0 \%$ & $6,0 \%$ & $0,0 \%$ & $1,5 \%$ & $0,0 \%$ & $10,6 \%$ & $11,4 \%$ & $8 \%$ \\
\hline Argentina & $3,3 \%$ & $3,4 \%$ & $6,1 \%$ & $0,0 \%$ & $0,0 \%$ & $0,0 \%$ & $15,5 \%$ & $15,5 \%$ & $15 \%$ \\
\hline Brazil & $3,9 \%$ & $5,1 \%$ & $3,3 \%$ & $0,0 \%$ & $0,0 \%$ & $0,0 \%$ & $7,2 \%$ & $6,9 \%$ & $10 \%$ \\
\hline China & $1,8 \%$ & $3,1 \%$ & $5,1 \%$ & $0,4 \%$ & $0,2 \%$ & $0,2 \%$ & $14,7 \%$ & $5,4 \%$ & $8 \%$ \\
\hline Chinese Taipei & $11,5 \%$ & $11,0 \%$ & $10,8 \%$ & $0,0 \%$ & $0,0 \%$ & $0,0 \%$ & $23,1 \%$ & $31,5 \%$ & $30 \%$ \\
\hline India & $2,1 \%$ & $4,0 \%$ & $2,6 \%$ & $1,7 \%$ & $3,7 \%$ & $0,0 \%$ & $9,5 \%$ & $10,4 \%$ & $9 \%$ \\
\hline Indonesia & $7,3 \%$ & $12,1 \%$ & $10,2 \%$ & $2,6 \%$ & $2,0 \%$ & $1,8 \%$ & $12,4 \%$ & $13,7 \%$ & $11 \%$ \\
\hline Israel & $11,0 \%$ & $15,4 \%$ & $14,6 \%$ & $0,0 \%$ & $0,0 \%$ & $0,0 \%$ & $10,1 \%$ & $19,0 \%$ & $19 \%$ \\
\hline Russian Fed. & $13,9 \%$ & $15,2 \%$ & $13,9 \%$ & $0,7 \%$ & $0,4 \%$ & $0,4 \%$ & $9,2 \%$ & $12,5 \%$ & $12 \%$ \\
\hline Singapore & $28,4 \%$ & $24,3 \%$ & $26,3 \%$ & $0,0 \%$ & $0,0 \%$ & $0,0 \%$ & $37,7 \%$ & $35,8 \%$ & $39 \%$ \\
\hline South Africa & $6,7 \%$ & $8,0 \%$ & $9,5 \%$ & $0,0 \%$ & $0,0 \%$ & $0,0 \%$ & $19,5 \%$ & $24,1 \%$ & $18 \%$ \\
\hline Hong Kong & $4,9 \%$ & $3,8 \%$ & $2,5 \%$ & $0,0 \%$ & $0,0 \%$ & $0,0 \%$ & $6,6 \%$ & $5,3 \%$ & $4 \%$ \\
\hline Chile & $10,5 \%$ & $12,1 \%$ & $14,4 \%$ & $0,0 \%$ & $0,0 \%$ & $0,0 \%$ & $27,4 \%$ & $22,8 \%$ & $23 \%$ \\
\hline Estonia & $26,4 \%$ & $20,5 \%$ & $22,6 \%$ & $8,5 \%$ & $1,9 \%$ & $2,3 \%$ & $50,1 \%$ & $37,4 \%$ & $35 \%$ \\
\hline Slovenia & $24,3 \%$ & $21,9 \%$ & $23,7 \%$ & $3,5 \%$ & $4,0 \%$ & $4,1 \%$ & $35,5 \%$ & $36,3 \%$ & $31 \%$ \\
\hline Malaysia & $25,9 \%$ & $19,9 \%$ & $19,0 \%$ & $11,3 \%$ & $2,2 \%$ & $2,8 \%$ & $35,9 \%$ & $42,3 \%$ & $42 \%$ \\
\hline Philippines & $10,5 \%$ & $13,3 \%$ & $16,5 \%$ & $0,0 \%$ & $0,0 \%$ & $0,0 \%$ & $24,0 \%$ & $35,5 \%$ & $35 \%$ \\
\hline Thailand & $13,5 \%$ & $14,4 \%$ & $5,1 \%$ & $2,4 \%$ & $0,0 \%$ & $0,5 \%$ & $22,4 \%$ & $32,3 \%$ & $36 \%$ \\
\hline Romania & $10,1 \%$ & $8,5 \%$ & $9,7 \%$ & $0,9 \%$ & $0,0 \%$ & $0,0 \%$ & $17,5 \%$ & $32,5 \%$ & $38 \%$ \\
\hline Vietnam & $4,0 \%$ & $11,8 \%$ & $13,0 \%$ & $0,0 \%$ & $0,0 \%$ & $0,0 \%$ & $12,9 \%$ & $12,9 \%$ & $13 \%$ \\
\hline Saudi Arabia & $13,7 \%$ & $23,5 \%$ & $26,5 \%$ & $5,4 \%$ & $6,9 \%$ & $7,4 \%$ & $17,2 \%$ & $38,6 \%$ & $41 \%$ \\
\hline
\end{tabular}

Source: OECD Input-Output Tables and authors' calculations. 


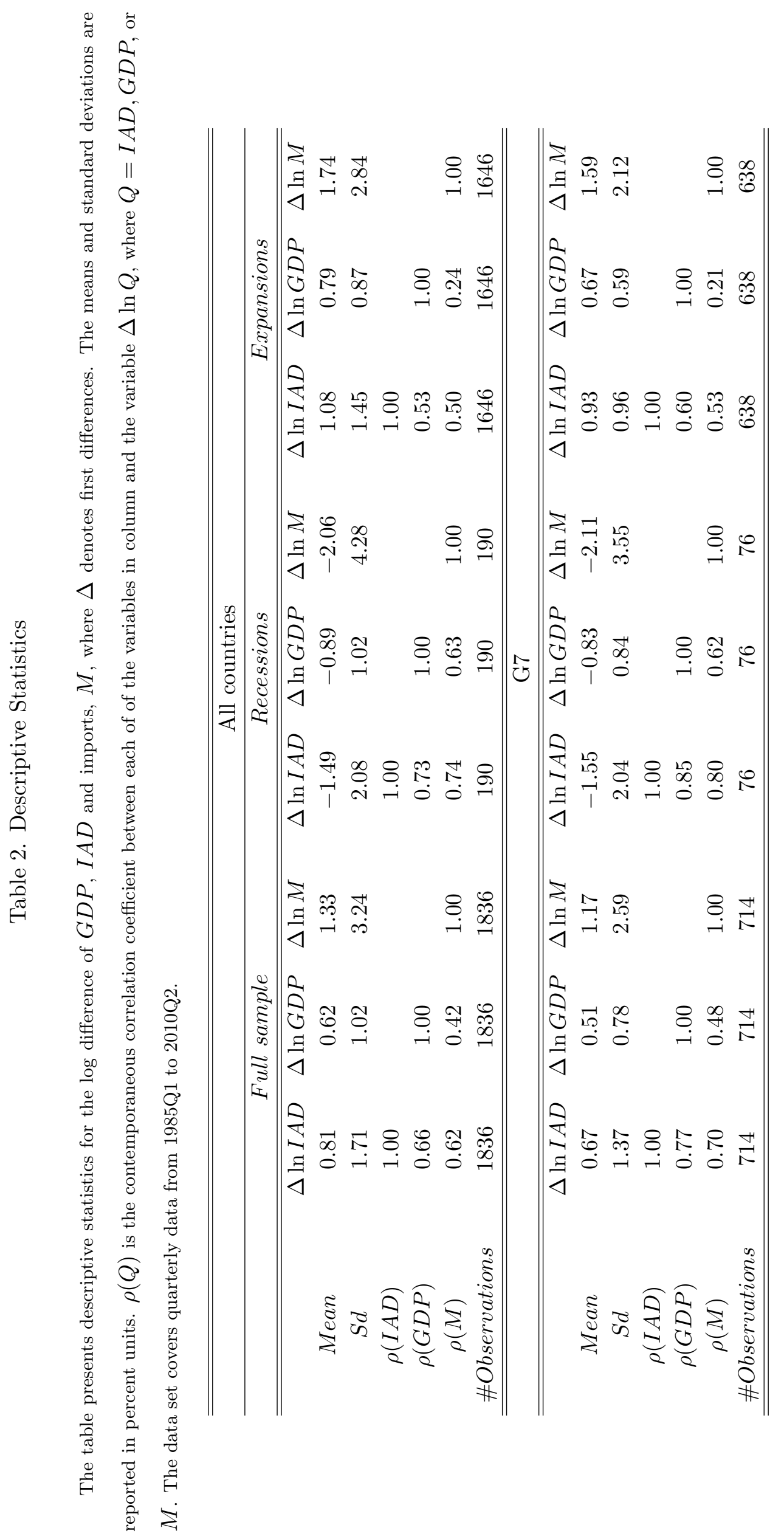


Table 3: Panel Results

The table reports in-sample estimates of panel regressions of the form (15) performed on our set of 18 countries and on the G7 countries, respectively. The dependent variable is the quarterly growth rate of real imports of goods and services. Three models are compared in the table, according to the demand measure $D$ used in each regression, where $I A D$ stands for our new import intensity-adjusted measure of demand, $G D P$ for real GDP, and $D D$ for real domestic demand. $P_{M}$ are relative import prices. To save space we do not report here the point estimates of the constant, and of the lagged values of the dependent variable and $P_{M} . R^{2}$ is the in-sample coefficient of determination. Robust standard errors are reported in parentheses. ${ }^{*},{ }^{* *}$, and ${ }^{* * *}$ indicate significance at the $10 \%, 5 \%$, and $1 \%$ levels, respectively. The analysis uses quarterly data from 1985Q1 to 2010Q2.

\begin{tabular}{|c|c|c|c|c|c|c|}
\hline & \multicolumn{6}{|c|}{ All countries } \\
\hline & \multicolumn{2}{|c|}{$I A D$ specification } & \multicolumn{2}{|c|}{$G D P$ specification } & \multicolumn{2}{|c|}{$D D$ specification } \\
\hline & 0 lags & $1 \mathrm{lag}$ & 0 lags & $1 \mathrm{lag}$ & 0 lags & $1 \mathrm{lag}$ \\
\hline \multirow[t]{2}{*}{$\Delta \ln (D)_{t}$} & $1.18^{* * *}$ & $1.22^{* * *}$ & $1.34^{* * *}$ & $1.33^{* * *}$ & $1.48^{* * *}$ & $1.55^{* * *}$ \\
\hline & $(0.0978)$ & $(0.0711)$ & $(0.2872)$ & $(0.2423)$ & $(0.1393)$ & $(0.0827)$ \\
\hline \multirow[t]{2}{*}{$\Delta \ln (D)_{t-1}$} & & $0.50^{* * *}$ & & $0.88^{* * *}$ & & $0.58^{* * *}$ \\
\hline & & $(0.0483)$ & & $(0.1376)$ & & $(0.1280)$ \\
\hline \multirow[t]{2}{*}{$\Delta \ln \left(P_{M}\right)_{t}$} & $-0.17^{* * *}$ & $-0.18^{* * *}$ & $-0.14^{*}$ & $-0.15^{* *}$ & -0.05 & -0.07 \\
\hline & $(0.05564)$ & $(0.0477)$ & $(0.0721)$ & $(0.0615)$ & $(0.0736)$ & $(0.0609)$ \\
\hline$R-s q$ & 0.40 & 0.46 & 0.19 & 0.26 & 0.26 & 0.30 \\
\hline \multirow[t]{4}{*}{ \#Observations } & 1836 & 1836 & 1836 & 1836 & 1836 & 1836 \\
\hline & \multicolumn{6}{|c|}{ G7 } \\
\hline & \multicolumn{2}{|c|}{ IAD specification } & \multicolumn{2}{|c|}{ GDP specification } & \multicolumn{2}{|c|}{$\overline{D D D}$ specification } \\
\hline & 0 lags & $1 \mathrm{lag}$ & 0 lags & $1 \mathrm{lag}$ & 0 lags & $1 \operatorname{lag}$ \\
\hline \multirow[t]{2}{*}{$\Delta \ln (D)_{t}$} & $1.35^{* * *}$ & $1.26^{* * *}$ & $1.60^{* * *}$ & $1.27^{* * *}$ & $1.62^{* * *}$ & $1.50^{* * *}$ \\
\hline & $(0.1021)$ & $(0.0851)$ & $(0.1996)$ & $(0.1221)$ & $(0.2292)$ & $(0.1617)$ \\
\hline \multirow[t]{2}{*}{$\Delta \ln (D)_{t-1}$} & & $0.47^{* * *}$ & & $0.90^{* * *}$ & & $0.63^{* * *}$ \\
\hline & & $(0.1096)$ & & $(0.1884)$ & & $(0.1509)$ \\
\hline \multirow[t]{2}{*}{$\Delta \ln \left(P_{M}\right)_{t}$} & $-0.11^{* *}$ & $-0.14^{* * *}$ & -0.01 & -0.04 & 0.09 & 0.03 \\
\hline & $(0.0371)$ & $(0.0340)$ & $(0.0540)$ & $(0.0375)$ & $(0.0469)$ & $(0.0478)$ \\
\hline$R-s q$ & 0.51 & 0.54 & 0.25 & 0.32 & 0.27 & 0.32 \\
\hline \#Observations & 714 & 714 & 714 & 714 & 714 & 714 \\
\hline
\end{tabular}


Table 4. Import Growth Decomposition - 2009Q1

The second column reports quarterly import growth in 2009Q1 for the 18 countries in our panel; Columns 3 to 8 report the percentage of import growth explained by the explanatory variables $I A D$ and $P_{M}$ in equation (15) and by each demand component in $I A D$ (notice that the sum of the contributions of $C, X, I$ and $G$ is equal to the contribution of $I A D)$. The last column shows the percentage of import growth explained by $G D P$. Negative values indicate that the explanatory variable account for import growth in the opposite direction of the one observed.

\begin{tabular}{l|c|c|cccc|c||c}
\hline \multicolumn{1}{c}{} & \multicolumn{8}{c}{ Percentage of import growth explained by : } \\
\hline & Import Growth (\%) & IAD & $C$ & $X$ & $I$ & $G$ & $P_{M}$ & $G D P$ \\
\hline U.S. & -10.9 & 80.6 & 1.4 & 31.4 & 47.7 & 0.2 & -13.0 & 30.0 \\
UK & -7.7 & 93.2 & 9.8 & 37.0 & 46.3 & 0.1 & 5.7 & 65.8 \\
Japan & -18.5 & 93.1 & 2.7 & 73.9 & 17.5 & -0.9 & -11.9 & 44.8 \\
Germany & -5.5 & 158.9 & -1.0 & 94.8 & 68.2 & -3.1 & -16.0 & 122.7 \\
France & -6.0 & 89.8 & -0.5 & 70.5 & 21.7 & -1.9 & -9.6 & 58.1 \\
Italy & -9.7 & 103.9 & 4.4 & 69.8 & 29.7 & 0.0 & -10.9 & 59.8 \\
Canada & -12.2 & 70.3 & 1.5 & 31.5 & 38.5 & -1.2 & -1.8 & 26.1 \\
Australia & -7.7 & 11.9 & -1.7 & -4.7 & 18.9 & -0.6 & -5.1 & -4.3 \\
Spain & -7.6 & 95.2 & 7.8 & 54.1 & 36.2 & -2.8 & -10.5 & 41.3 \\
Netherlands & -5.6 & 101.9 & 8.9 & 53.6 & 41.8 & -2.5 & -3.8 & 76.6 \\
Porugal & -11.4 & 90.5 & 6.0 & 51.5 & 35.1 & -2.1 & -5.0 & 32.1 \\
Norway & -16.2 & 27.3 & 3.0 & 3.4 & 23.4 & -2.5 & 4.0 & 4.4 \\
NewZealand & -7.5 & 57.1 & 4.5 & 2.0 & 51.9 & -1.3 & -10.6 & 20.6 \\
Sweden & -6.8 & 158.6 & 2.9 & 48.8 & 109.3 & -2.6 & -1.0 & 108.2 \\
Belgium & -6.7 & 86.6 & 3.7 & 61.1 & 21.7 & 0.1 & -16.5 & 63.1 \\
Finland & -13.1 & 97.3 & 3.5 & 69.5 & 25.3 & -1.0 & -11.2 & 82.4 \\
Denmark & -8.5 & 44.9 & 12.2 & 27.7 & 6.7 & -1.8 & -9.5 & 53.1 \\
Korea & -6.7 & 63.7 & 7.2 & 50.2 & 13.1 & -6.7 & -26.7 & 56.7 \\
\hline \hline
\end{tabular}




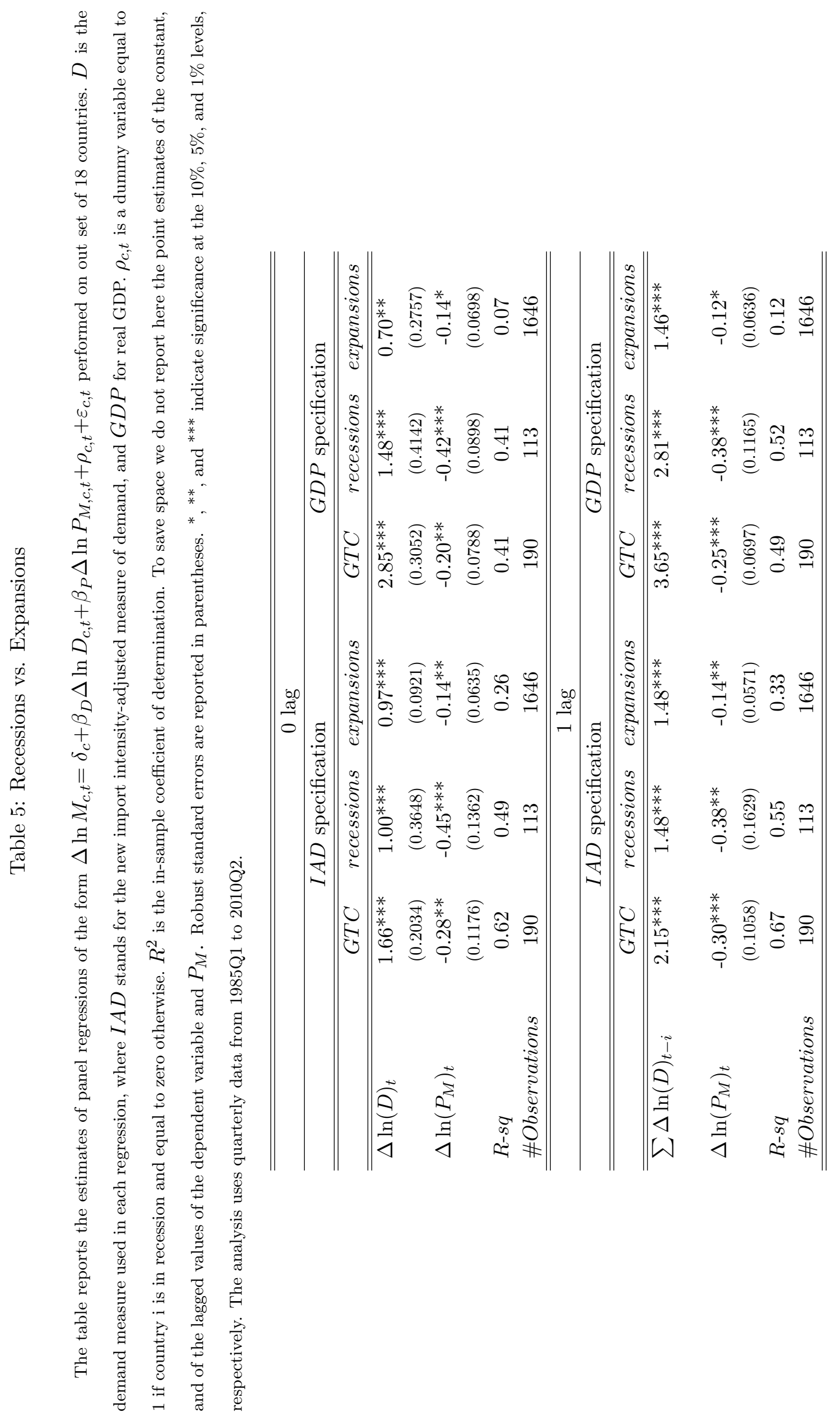

